\title{
Launching for Success: The Effects of Psychological Distance and Mental Simulation on Funding Decisions and Crowdfunding Performance
}

March 15, 2020

\author{
Stefan Rose ${ }^{\mathrm{a}}$, Daniel Wentzel ${ }^{\mathrm{a}}$, Christian Hopp $^{\mathrm{a}}$, Jermain Kaminski ${ }^{\mathrm{b}}$
}

\begin{abstract}
This research examines how potential backers form mental representations of products in rewardbased crowdfunding campaigns, and how these representations affect funding decisions and campaign performance. To test our framework, we conducted four experiments and also drew on a sample of 961 Kickstarter campaigns. Our results show that two campaign characteristics - the product's development stage and the indicated time to product delivery - determine the psychological distance that supporters experience in response to a campaign, and that psychological distance, in turn, inhibits individual campaign contributions and cumulative campaign success. Furthermore, we find that encouraging supporters to imagine the benefits of product usage is an effective means to increase support for campaigns that elicit high psychological distance.
\end{abstract}

Keywords: crowdfunding, new product development, entrepreneurial financing, construal level theory, psychological distance, mental simulation

\section{Introduction}

New products often originate from the ideas of creative entrepreneurs, who, instead of being guided by what is in the present, develop ventures around their own visions of the future (Dimov, 2010). These new venture ideas include "imaginary combinations of product/service offerings, potential markets or users, and means of bringing these offerings into existence" (Davidsson, 2015: 675). To be able to realize their ideas, entrepreneurs often need to acquire funding from external sources. A funding source that has gained in popularity in recent years is reward-based

\footnotetext{
${ }^{a}$ RWTH Aachen University, School of Business and Economics, Kackertstraße 7, 52072 Aachen, Germany. \{rose, wentzel, hopp\}@time.rwth-aachen.de

b Maastricht University, School of Business and Economics, Tongersestraat 53, 6211 LM Maastricht, Netherlands. \{j.kaminski\}@maastrichtuniversity.nl
} 
crowdfunding. In reward-based crowdfunding, entrepreneurs bypass traditional sources of capital such as banks, business angels, and venture capitalists. Instead, they raise funds by directly addressing a large number of individuals and allowing them to pre-order a product in return for a financial contribution (Belleflamme et al., 2013). Pre-selling is endemic to crowdfunding and backers of crowdfunding campaigns can be considered the first customers a venture is going to have (Cholakova and Clarysse, 2015; Mollick, 2014).

However, what entrepreneurs sell and what backers buy on crowdfunding platforms are not tangible products but rather the possibility or idea of these products. That is, entrepreneurs imagine the possibility of a new product and communicate this idea through textual and visual information on campaign pages (Fisher et al., 2017). To acquire funding, crowdfunding entrepreneurs have to favorably shape the perceptions of backers and to "socially construct the conditions for consumer acceptance of a product that had no prior contextual understanding or awareness in the marketplace" (Suddaby et al., 2015: 3). Accordingly, crowdfunding campaigns often promote products that are in early stages of the development process, when the exact specifications of the to-be-developed product as well as the time needed to deliver it are uncertain (Stanko and Henard, 2017). For potential backers, this creates a unique decisional challenge: they need to decide if they want to pledge their funds to a product that does not exist and will only be realized if the campaign is successful (Frederiks et al., 2019). As they cannot experience the proposed product directly, they need to form a mental representation of the product and base their funding decision on this representation rather than on the actual product.

As we will argue in this study, this idiosyncrasy of reward-based crowdfunding is important for campaign performance. Research in psychology has demonstrated that people's evaluations of a stimulus, such as a product, depend greatly on whether they can experience the stimulus directly, such as by seeing or touching it, or whether they have to rely on a mental representation 
of this stimulus (Hamilton and Thompson, 2007; Trope and Liberman, 2003; 2010). Thus, in order to assess how backers arrive at their funding decisions and how entrepreneurs may shape these decisions to their favor, it is important to gain a fuller understanding of how backers form mental representations of the products pitched in crowdfunding campaigns, and how these representations are related to their subsequent decision processes. The aim of this research is to understand (a) how mental representations affect funding decisions on an individual level and the effectiveness of campaigns on an aggregate level, and (b) how entrepreneurs can match their communication efforts to their backers' representations.

To address the first question, we develop a conceptual framework based on Construal Level Theory (CLT, Trope and Liberman, 2010). CLT argues that a stimulus that is not part of a person's direct experience has to be mentally construed (i.e., imagined) and thus feels "distant" in a psychological sense. Moreover, CLT predicts that the evaluation of such a stimulus is contingent on the specific nature of the mental representation that a person forms of it (Dhar and Kim, 2007). Building on these arguments, we postulate (a) that backers' responses to a product displayed in a crowdfunding campaign are contingent on the psychological distance they feel towards it, and (b) that psychological distance, in turn, is determined by the structural characteristics of the campaign promoting the product. Based on CLT, we argue that campaigns that feature products that are in the early stages of the development process or indicate that it will take a long time to deliver the product will feel psychologically more distant. This feeling is likely to affect campaign outcomes, as psychological distance will reduce individual campaign contributions and the performance of campaigns in the aggregate.

To address our second question, we introduce the concept of mental simulation, the imitative mental representation of a stimulus, such as a product. We argue that entrepreneurs may improve responses to their campaigns by tailoring their communication to their backers' mental 
representations. Specifically, we postulate that encouraging potential backers to engage in particular types of mental simulation creates a match between the psychological distance of the product - nearer or farther away - and the backers' processing of the campaign. A total of four controlled experiments and a sample of field data from Kickstarter provide converging evidence for these predictions.

With our findings, we make several contributions to the literature on crowdfunding and entrepreneurial resource acquisition.

First, we contribute to research studying the uncertainties that potential resource providers face in their funding decisions. We demonstrate that the mental representations that potential backers form of a product depend on the campaign's structural characteristics, and that these representations, in turn, affect performance. Our research shows that resource contributions in crowdfunding are a function of psychological distance and that campaigns that trigger higher degrees of distance are generally less effective.

Second, our research provides a new theoretical lens on entrepreneurial resource acquisition, showing that the communication of a campaign (i.e., the degree to which the presentation of a product focuses on the process or on the outcome of using it) must align with the mental representations of potential supporters. Going forward, this lens might be employed well beyond the crowdfunding context and prove equally applicable in other areas of venture financing such as business angel and/or venture capital financing.

Third, our research expands knowledge on how entrepreneurs can positively shape the assessments of their venture ideas in venture development. Our findings show how potential customers form mental representations of entrepreneurial visions at different stages of the venture development process and, by pointing to the role of mental simulations, lay out a framework for communicating the desirability of these visions effectively. 


\section{Theory and hypotheses}

\subsection{Reward-based crowdfunding: context and decision-making}

As many new ventures fail because entrepreneurs do not succeed in convincing potential financiers to provide capital, reward-based crowdfunding has emerged as an attractive alternative for acquiring funds. In reward-based crowdfunding, entrepreneurs directly address the crowd, allowing their supporters to pre-purchase proposed products in order to finance their realization (Belleflamme et al., 2013). From the perspective of potential funders, the decision whether or not to support a crowdfunding campaign is associated with considerable uncertainty: they need to decide if they want to commit their money to a product that does not yet exist and that they will receive after a temporal delay, once the campaign is completed and the product is successfully developed.

In order for their campaigns to succeed, entrepreneurs must shape the perceptions of their supporters to their benefit. To do so, they may use a range of different cues and tactics, including product-related arguments, information about their own background, emotionally charged narratives, and the use of positive language and rhetorical techniques (e.g., Allison et al., 2017; Anglin et al., 2018a; Anglin et al., 2018b; Davis et al., 2017; Li et al., 2017; Mollick, 2014). In our study, we build on this line of research by examining how potential backers form mental representations of the products featured in crowdfunding campaigns and how entrepreneurs can shape these representations through eliciting different types of mental simulation. To develop our conceptual framework, we draw on CLT, which examines how people form mental representations of stimuli they cannot experience directly. 


\subsection{Mental construal and psychological distance in reward-based crowdfunding}

CLT argues that an individual's psychological distance to a stimulus determines how that stimulus is mentally represented or construed (Trope and Liberman, 2010). When the psychological distance to a stimulus (an event, a decision, a person, or an object) is high, people are more likely to form an abstract, high-level representation of this stimulus that focuses on its general meaning. When, however, psychological distance is low, individuals will tend to form a concrete, low-level representation of the stimulus that involves very detailed and contextdependent information (Liberman and Trope, 1998; Trope and Liberman, 2003, 2010; Trope et al., 2007). Moreover, CLT does not only describe how psychological distance may affect mental representations, but also argues that the psychological distance experienced in response to a stimulus is determined by the objective distance to that stimulus. Early work in this area has focused on temporal distance, arguing that events that are more distant in a temporal sense will also feel more distant in a psychological sense (Liberman and Trope 1998; Trope and Liberman 2003). For example, an event that will take place in a more distant future (e.g., next year's vacation) will feel more psychologically distant than an event taking place in the near future (e.g., next week's vacation).

However, subsequent research found that psychological distance may not only be shaped by temporal distance but also by three other types of distance, namely spatial distance, social distance, and hypothetical distance. While these dimensions may naturally correlate, each of the four dimensions is conceptually and empirically distinct (Henderson et al., 2011; Huang et al., 2016; Liberman and Trope, 2014; Trope et al., 2007). Put differently, each of the four dimensions exerts an independent impact on an overall sense of psychological distance.

Drawing on research on CLT, we argue that backers' mental representations of a proposed product will be informed by the psychological distance they feel towards the product, and that 
psychological distance, in turn, will be determined by the campaign's idiosyncratic properties. Two of the distance dimensions that form part of CLT - hypotheticality and temporal distance are of crucial relevance in the context of reward-based crowdfunding.

First, regarding hypotheticality, a product's development process is an often-invoked narrative on crowdfunding campaign sites (Manning and Bejarano, 2017; Murray et al., 2020). Yet, campaigns that are launched on crowdfunding platforms differ with regard to the progress of their proposed product. Stanko and Henard (2017) report that campaigns that apply for funding have completed, on average, about 60 percent of their new product development activities. About 30 percent of the ventures have completed less than 50 percent of new product development activities at the time of the campaign. That is, while some entrepreneurs launch their campaigns when they have completed the development process and need funds to realize the production process, others address the public right after they have conceptualized the product and/or have developed a prototype, thus calling for funds that will be necessary for financing the remaining steps of the development process. All other things being equal, campaigns displaying products in an earlier development stage will feel more hypothetical because they feature a product that only exists in a preliminary form and because the final outcome of the development process may be somewhat unclear. As a result of this increased hypotheticality, the product is likely to perceived as more psychologically distant (Trope and Liberman, 2010).

Second, regarding temporal distance, any product originating from a crowdfunding campaign is delivered after a time delay: only when the campaign is successful and the entrepreneur has the funds for realizing his/her vision can the product be produced and shipped. While such delays are inherent to reward-based crowdfunding, the amount of time that is needed to deliver the product varies across different campaigns (Mollick and Kuppuswamy, 2014). For instance, the Kickstarter campaign for a 3D printer called The Micro promised to deliver its 
products to consumers seven months after the completion of the campaign, whereas the Coolest Cooler campaign indicated it would need just around two months to produce and ship its products. Again, all other things being equal, campaigns that indicate a longer time to realize the proposed outcome will feel psychologically more distant because the temporal distance between the funding decision and product delivery is higher (Liberman and Trope, 1998). ${ }^{3}$

According to CLT, when pondering goal-directed action, individuals make a distinction between desirability concerns and feasibility concerns. While desirability concerns focus on the value of an action's end state (i.e., the "why" of pursuing an action), feasibility concerns involve the means that are necessary for reaching that state (i.e., the "how" of performing that action) (Trope and Liberman, 2010). The extent to which people focus on desirability or feasibility is strongly influenced by how psychologically distant an action is. As noted above, when the psychological distance to a stimulus is high, people tend to form an abstract, high-level representation of the stimulus that focuses on its general meaning. When, however, psychological distance is low, individuals tend to form a concrete, low-level representation of the stimulus that involves detailed and context-dependent information. Thus, CLT predicts that "desirability concerns should receive greater weight over feasibility concerns as psychological distance increases" (Trope et al., 2007: 89).

When evaluating a product featured in a crowdfunding campaign, the extent to which supporters focus on desirability-related or feasibility-related aspects may depend on the psychological distance they feel between themselves and the product. Potential backers will likely focus more on desirability - the benefits of using the product - when the product is in an

\footnotetext{
${ }^{3}$ Arguably, in real campaigns these two dimensions may naturally correlate. That is, campaigns that are in a less advanced development stage will typically take longer to be realized and vice versa. Nonetheless, both dimensions are conceptually independent from each other and are thus theorized, operationalized, and tested independently in our research. For instance, a campaign that features an early-stage product may nonetheless be realized very quickly given the appropriate resources, whereas a campaign that presents a very advanced product may still take a long time to deliver the product due to unforeseen delays or a lack of resources in the final stages of the development process.
} 
early development stage or when the product will be delivered in the distant future, while they will likely focus more on feasibility - the process that would be necessary for using the product when the product is in a more advanced development stage or when the product will be delivered in the near future.

\subsection{The effect of psychological distance on campaign outcomes}

If funders place different weights on desirability or feasibility concerns when assessing products that trigger higher or lower levels of distance, then they may also differ in their intention to contribute to the corresponding campaigns. While backers evaluating psychologically distant campaigns may concentrate more strongly on the benefits of the product, they may also experience greater uncertainty with respect to these benefits (Castaño et al., 2008; Hoeffler, 2003). Prospective backers do not only need to assess the benefits of a product whose attributes are not yet fully developed (e.g., when the product is in an early stage); they also need to consider if they will have a need for these benefits in the distant future (e.g., when the indicated time to delivery is long). That is, they may experience uncertainty because they find it difficult to predict the merits of a highly hypothetical product and/or the exact nature of their future preferences (Hamilton and Thompson, 2007; Simonson, 1990; Thompson et al., 2005). This uncertainty, in turn, will undercut the desirability of the product and the prospective backers' willingness to contribute to the campaign (Alexander et al., 2008; Hoeffler, 2003).

In contrast, supporters who evaluate campaigns that are psychologically closer are likely to focus more on the process of using the product than on its potential benefits; yet, they may also experience uncertainty with regard to this process. Adopting a new product frequently involves learning costs, as consumers may need to learn new patterns of behavior. These learning costs can act as a deterrent to new product adoption (Castaño et al., 2008; Hoeffler, 2003). Hence, 
funders who are confronted with a campaign that promotes a product that is fully developed and will be available in the immediate future may be concerned with the costs and drawbacks associated with adopting the product, and these concerns may negatively affect their funding decisions.

While both kinds of uncertainty are likely to undermine a person's willingness to support a campaign, we argue that uncertainties about outcomes will have a stronger effect than uncertainties about processes. As such, "people are always sensitive to the larger meanings, effects, and implications of what they are doing" (Vallacher and Wegner, 1987: 5). Importantly, as ends (such as the benefits associated with consumption) are superordinate to means (such as the processes that are necessary to realize these benefits), individuals are more sensitive to changes in ends than to changes in means (Thompson et al., 2009). Thus, we argue that backers are less likely to support campaigns that trigger higher desirability concerns (i.e., campaigns that are less advanced or indicate a long delivery time) than they are to support campaigns that trigger higher feasibility concerns (i.e., campaigns that are more advanced or claim to deliver the product promptly). We further argue that these effects will be mediated by the psychological distance that potential backers experience in response to the campaigns. Hence,

H1: Reward-based crowdfunding campaigns that (a) display products in a less advanced development stage or (b) claim to deliver the products in the distant future are less likely to receive support from potential backers.

H2: The effects of product development stage and time to delivery on willingness to support are mediated by psychological distance. 


\subsection{Improving campaign-audience alignment through mental simulation}

Next, we discuss how entrepreneurs should engage with their supporters to enhance the effectiveness of their campaigns. As elaborated above, if they want to realize their visions, entrepreneurs need to persuade potential backers to pledge their funds to a product that does not exist yet. Previous research has identified several persuasive techniques that entrepreneurs use to increase support for their ventures (e.g., Allison et al., 2017; Anglin et al., 2018a; Anglin et al., 2018b; Parhankangas and Renko, 2017). Extending these findings, we argue that to increase support for their campaigns, entrepreneurs' communicative efforts need to be congruent with the mental representations that potential backers form of a product.

One way to achieve this congruence is to encourage the potential backers to engage in different forms of mental simulation. Mental simulation refers to the imitative mental representation of an event or a series of events (Taylor et al., 1998). In consumption-related contexts, mental simulation can be triggered by the way in which product-related information is presented, and it helps consumers imagine how they would interact with a product they have not yet experienced directly (Krishnamurthy and Sujan, 1999). The literature distinguishes between two forms of mental simulation: process simulation and outcome simulation (Castaño et al., 2008; Escalas and Luce, 2004; Taylor et al., 1998; Wentzel et al., 2010; Zhao et al., 2007).

Process simulation means imagining the step-by-step process of carrying out an activity (in this case, using a new product), whereas outcome simulation means imagining the benefits achieved by carrying out an activity (in this case, the positive outcomes arising from the use of a new product). Process simulation can be thought of as a detailed step-by-step narrative where carrying out action $a$ before action $b$ leads to the achievement of outcome $c$. Thus, process simulation is very concrete and rich in detail. In contrast, outcome simulation highlights the end state of the narrative. That is, the actions necessary to achieve the end state are considered as 
having occurred and the step-by-step process is not necessarily considered. As a result, outcome simulation typically leads to more abstract mental representations (Escalas and Luce, 2004). In other words, process-focused simulation resembles how-thinking, while outcome-focused simulation resembles why-thinking.

While both kinds of mental simulation may improve responses to new products (e.g., Escalas and Luce, 2004), the effectiveness of process and outcome simulation also depends on psychological distance. Individuals who expect to consume a product in the distant future are likely to feel uncertain about the utility of the product. Focusing people's attention on the benefits of product use - outcome simulation - is an effective means to address these uncertainties (Castaño et al., 2008). In contrast, people expecting to consume a product in the near future are more concerned about the drawbacks relating to how to use the product. As a result, process simulation that focuses people's attention on the steps necessary to use the product will help to improve consumer responses to new products (Zhao et al., 2007).

In crowdfunding, backers who are confronted with products that feel psychologically distant (because the products are still in an early phase or will need a long time to be delivered) will be more focused on desirability-related aspects; that is, they will be more concerned with the benefits of the proposed product (Castaño et al., 2008; Zhao et al., 2007). In such cases, encouraging them to engage in outcome simulation - imagining the benefits they would enjoy by using the product - should be more effective in improving their willingness to contribute. As psychologically distant campaigns are likely to be construed in more abstract, superordinate terms, guiding backers' attention to the "why" of consumption and encouraging them to reflect about the benefits of the proposed outcome should be more congruent with the abstract mental representations that they naturally form.

However, for products that feel psychologically close (because the products are in a more 
advanced development stage or will be delivered in the near future) potential supporters may feel more confident about the products' benefits. In line with this notion, Murray et al. (2020) found that backers that learn about a campaign at a later stage of the development process have a more consumer-oriented and transactional mindset. As a result, encouraging potential supporters to engage in outcome simulation may do little to improve their willingness to contribute to the campaigns. Yet, backers may be more concerned about feasibility-related aspects of the product, and may thus benefit more strongly from process-focused mental simulation (Castaño et al., 2008; Zhao et al., 2007). Focusing their attention on the "how" of consumption and encouraging them to think of the process of using the product will be more congruent with the concrete, contextualized representations of campaigns that feel psychologically close.

In sum, we postulate that mental simulation interacts with the psychological distance associated with the product to affect the willingness to contribute to a campaign. If a campaign displays a product in an early development stage or indicates a long delivery time, potential backers will report a higher willingness to contribute to the campaign when they are encouraged to engage in outcome-focused simulation. If, on the other hand, the campaign features a product in a more advanced development stage or indicates a short delivery time, backers will exhibit a higher willingness to contribute to the campaign when they are encouraged to engage in processfocused simulation. Thus,

H3a: For campaigns that (a) display products in a less advanced development stage or (b) claim to deliver the product in the distant future, outcome simulation will lead to a greater willingness to contribute to the campaign than will process simulation.

H3b: For campaigns that (a) display products in a more advanced development stage or (b) claim to deliver the product in the near future, process simulation will lead to a greater willingness to contribute to the campaign than will outcome simulation. 
Our conceptual model is summarized in Figure 1.

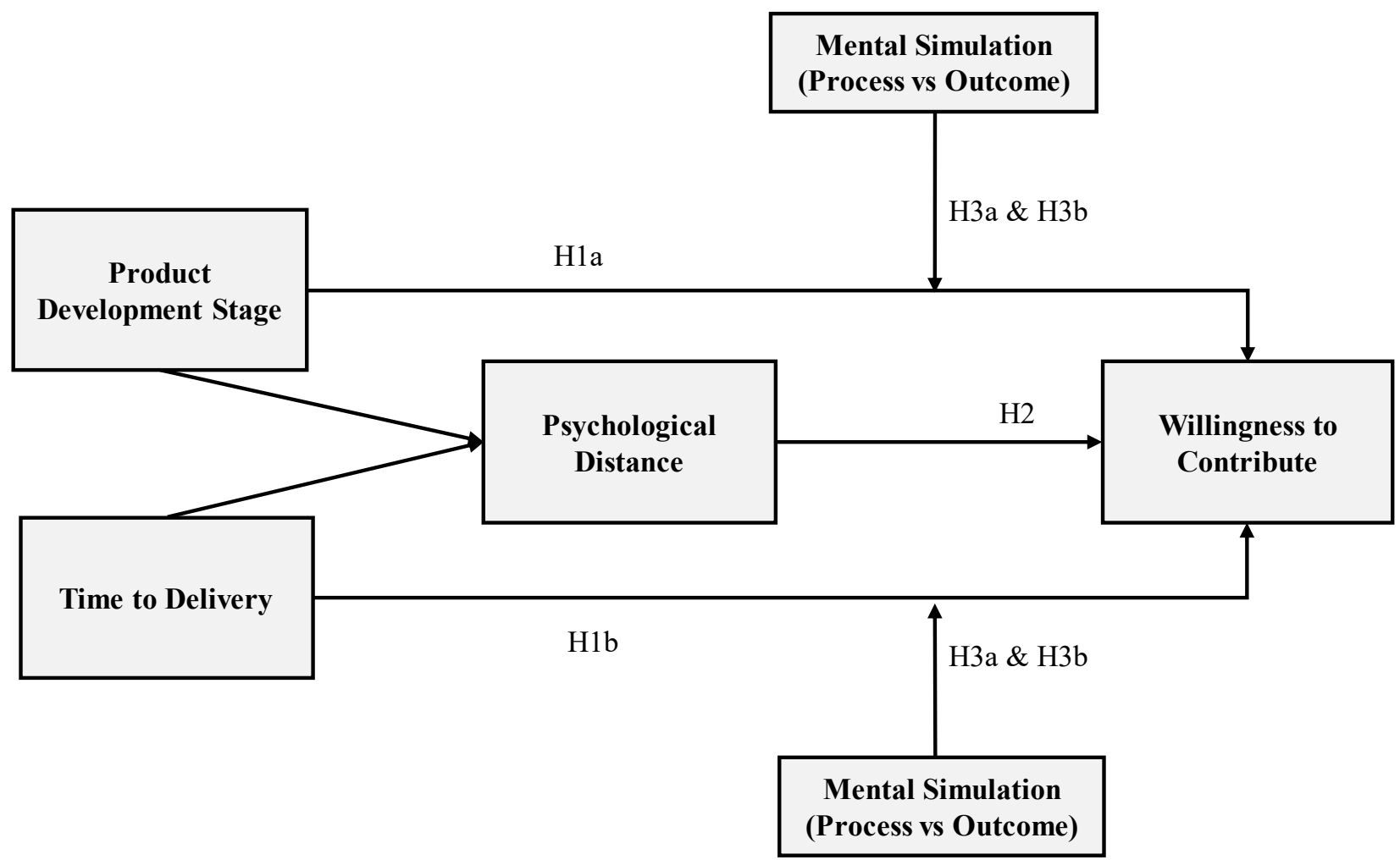

Figure 1: Conceptual Model

\section{Pretests: Establishing mental representations of crowdfunding campaigns}

One of the key assumptions of our framework is that crowdfunding campaigns that feature products that are in a less advanced development stage or indicate that it will take longer to deliver the product will elicit greater psychological distance. Although previous studies have demonstrated that hypothetical as well as temporal distance are indeed linked with psychological distance (Trope and Liberman, 2010), we wanted to test this critical assumption through two pretests before proceeding to test our more specific hypotheses.

\subsection{Pretest 1: Hypothetical distance}

In the first pretest, we tested whether the development stage of a product was associated with psychological distance. To this end, we recruited 135 individuals $(46.7 \%$ female, average 
age: 38.1 years) by street intercept and invited them to a behavioral lab at a German university. Participants were presented with two actual Kickstarter campaigns: Amabrush, a toothbrush that, according to its designers, is capable of brushing all one's teeth at once, and Pro Drybag, a waterand shockproof sports bag. The development stage of these products was manipulated between participants. Participants were either exposed to a campaign version where the products were in an early stage or one where the products were in a more advanced stage. For example, in the early-stage condition, participants read that the founders had developed an initial prototype that they were now seeking to refine. In the market-ready condition, they read that the founders had finalized the entire development process and were now seeking to realize large-scale production. Moreover, we extracted images from the original campaigns and modified these images with image processing software to appear as conceptual sketches or market-ready products (more details on our manipulations are provided in the supplementary appendix).

After going through the campaigns, participants indicated how psychologically distant the campaigns felt to them ("Please imagine that you are considering pre-purchasing the proposed product. How far away do you feel from using and experiencing the product if you would prepurchase it now through the campaign?", 1 = "Very close" to 7 = "Very far away"). This item was adopted from Kim et al. (2008). Consistent with expectations, an ANOVA revealed a significant effect of product stage on psychological distance for both Amabrush ( $M_{\text {early-stage }}=$ $\left.4.04, M_{\text {market-ready }}=3.33, F(1,134)=4.18, p=.043\right)$ and Pro Drybag $\left(M_{\text {early-stage }}=4.34, M_{\text {market-ready }}\right.$ $=3.57, F(1,134)=5.58, p=.020)$.

Furthermore, participants were asked to provide an open-ended answer to the question "Please imagine yourself using this product. Try to think of what you would do and how you would experience the product.” This procedure was adapted from Liberman and Trope (1998). Two research assistants that were blind to the research question coded each individual answer as 
a why-focused (i.e., desirability-related) or a how-focused answer (i.e., feasibility-related). ${ }^{4}$

Interrater reliability between the coders was high (Amabrush: $K=0.76$; Pro Drybag: $K=0.73$ ). Again, we found a significant effect of product stage on construal level (Amabrush: $X^{2}(1)=$ 13.64, $p<.001$; Pro Drybag: $\left.X^{2}(1)=14.19, p<.001\right)$. Respondents in the early-stage conditions were more focused on thoughts about why they should use the product (Amabrush: 63.9\% whyfocus, Pro Drybag: $60.7 \%$ why-focus), while respondents in the market-ready conditions were predominantly focused on the how-related aspects (Amabrush: 69.4\% how-focus, Pro Drybag: $73.8 \%$ how-focus).

\subsection{Pretest 2: Temporal distance}

In the second pretest, we tested the relationship between time to delivery and psychological distance. A total of 113 participants (45.1\% female, average age: 34.5 years) located in the US were recruited through Amazon Mechanical Turk and were asked to evaluate two Kickstarter campaigns. In the interest of generalizability, we used different campaigns than in the first pretest: Dash, a wireless smart in-ear headphone, and Espro, a coffee/tea press that can be used to make coffee/tea while on the go. In this pretest, the time between the completion of the campaign and the delivery of the products was manipulated between participants. In the near future condition, participants read that the entrepreneurs planned to deliver the product within 30 days after successful completion of the campaign. In the distant future condition, they read that the product would be delivered within six months. After reading through the campaign descriptions, participants responded to the same questions as in the first pretest.

Lending support to our assumptions, an ANOVA revealed a significant effect of temporal

\footnotetext{
${ }^{4}$ Why-focused answers were counted as those answers that focused on the benefits of using the product, for example, "I will save my time brushing my teeth. It makes sense and makes life easier" (Amabrush). How-focused answers, on the other hand, were answers focusing on the usage process, for example, "I would use it as described: Insert mouthpiece, activate, and wait" (Amabrush).
} 
distance on psychological distance for both Espro $\left(M_{\text {near future }}=3.00, M_{\text {distant future }}=4.86, F(1,111)\right.$ $=45.10, p<.001)$ and Dash $\left(M_{\text {near future }}=3.09, M_{\text {distant future }}=4.19, F(1,111)=12.07, p=.001\right)$. Again, two research assistants coded participants' answers into why- and how-focused answers (Interrater reliability: Dash: $K=0.79$; Espro: $K=0.86$ ). We found a significant effect of temporal distance on construal level (Espro: $X^{2}(1)=6.10, p=.014$; Dash: $X^{2}(1)=4.33, p=.038$ ). Respondents who were told that the products would be delivered in six months focused more on why-thoughts (Espro: 64.2\% why-focus, Dash: 58.5\%), whereas participants who believed that the product would be delivered within 30 days focused more on how-thoughts (Espro: 60.4\% how-focus, Dash: 62.0\% how-focus).

\subsection{Conclusions of pretests}

The results of our pretests provide support for our key assumption, namely that the structural characteristics of a campaign affect the mental representation that backers form of the product pitched in the campaign. Potential backers felt that products that were in a less advanced development stage or that would deliver the products in the more distant future were psychologically more distant. They also focused more on desirability-related criteria than on feasibility-related criteria for evaluating these products.

\section{Study 1: Psychological distance and willingness to support}

\subsection{Study 1a: Hypothetical distance}

\subsubsection{Design, participants, and procedure}

Study 1a was designed to test $\mathrm{H} 1 \mathrm{a}$ and $\mathrm{H} 2$ and used a one-factorial design where product stage (early-stage vs. market-ready) was manipulated at two levels. A total of 103 individuals (45.6\% female) located in the US were recruited through Amazon Mechanical Turk and completed the study online. In the interest of validity, we ensured that our participants were 
representative of the broader crowdfunding population. Backers on crowdfunding platforms are typically younger and less experienced than traditional investors; one study has found that their average age is between 24 and 35 years (Fundable, 2014). Moreover, according to Kickstarter, backers are relatively inexperienced, with $67 \%$ of all backers being first-time funders

(Kickstarter, 2019). In this and the remaining studies, we assessed prior crowdfunding experience on a 7-point scale ranging from $1=$ "Not at all" to $7=$ "Very much." On average, participants in our sample were 38.0 years old and only $33.1 \%$ indicated that they were relatively experienced with crowdfunding (i.e., scoring between 5 and 7 on a 7-point scale). Hence, the characteristics of our sample match those of typical crowdfunding supporters. The procedure of the study followed the procedure used in the pretests.

\subsubsection{Independent variable}

In this and the remaining experimental studies, we relied on the Amabrush campaign that we had already used in the first pretest. We reasoned that this campaign was ideally suited for testing our hypotheses, as potential backers may experience considerable uncertainty with both the process as well as the outcome of using a fully automated toothbrush. Moreover, using the same campaign allowed for a common frame of reference for testing our hypotheses across different studies. The key manipulation, product stage, was operationalized in an identical manner as in the pretest.

\subsubsection{Measures}

Willingness to support. Willingness to support was measured with two items adapted from Ciuchta et al. (2016) ("Would you be willing to pre-order the proposed product via this campaign?" and "How likely would you support this campaign with a monetary contribution?") with anchors $1=$ "Not at all" to $7=$ "Definitely" $(\alpha=.93)$.

Psychological distance. Psychological distance was measured with the same item as in the 
pretests.

Covariate. To control for extraneous variance, we measured to what extent participants considered the product presented in the campaign - the toothbrush - to be of personal relevance to them. Relevance was measured with three 7-point items ("This campaign is of personal relevance to me," "I would like to own the product that is proposed in this campaign," "If the product proposed in this campaign was available in shops, I would buy it, $\left.{ }^{\prime} \alpha=.85\right)$.

\subsubsection{Results}

Willingness to support. An ANCOVA with willingness to support as the dependent variable revealed a significant effect of product stage on willingness to support $(F(1,100)=9.68, p=$ .002). Participants expressed a lower willingness to support the campaign when the product was in an early stage than when it was in a more advanced stage $\left(M_{\text {early-stage }}=3.48, M_{\text {market-ready }}=\right.$ 4.24), thus supporting H1a. Personal relevance emerged as a significant covariate $(F(1,100)=$ $210.18 p<.001)$

Process analysis. To test the underlying process, we conducted a mediation analysis using the PROCESS script (Hayes, 2013, model 4) with 5,000 bootstrap samples and 95\% confidence intervals. This analysis revealed a significant indirect effect of product stage on willingness to support through psychological distance $(b=.1955,95 \%$ confidence interval $[C I]=[.032, .424])$. These results provide support for $\mathrm{H} 2$.

\subsection{Study 1b: Temporal distance}

\subsubsection{Design, participants, and procedure}

The aim of Study $1 \mathrm{~b}$ was to test H1b and H2. Study $1 \mathrm{~b}$ used a one-factorial design where temporal distance (near future vs. distant future) was manipulated at two levels. A total of 101 participants (40.6\% female) recruited through Amazon Mechanical Turk completed the study 
online. Again, our sample was representative of typical crowdfunding supporters in terms of age $\left(\mathrm{M}_{\mathrm{age}}=35.0\right)$ and prior experience $(39.6 \%$ indicating that they were relatively experienced with crowdfunding). Except for the manipulation of temporal distance, the procedure of Study $1 \mathrm{~b}$ was identical to Study 1a.

\subsubsection{Independent variable}

Again, we relied on the Amabrush campaign. In the near future condition, participants were informed that the product would be delivered in 30 days. In the distant future condition, the time to delivery was expanded to nine months.

\subsubsection{Measures}

All measures were identical to Study 1a (willingness to support: $\alpha=.92$; personal relevance: $\alpha=.86$ ).

\subsubsection{Results}

Willingness to support. An ANCOVA revealed a significant effect of temporal distance on willingness to support the campaign $(F(1,98)=20.60, p<.001)$. In line with $\mathrm{H} 1 \mathrm{~b}$, participants were more willing to support the campaign when the product would be delivered after 30 days than after nine months $\left(M_{\text {near future }}=4.89, M_{\text {distant future }}=3.56\right)$. Again, personal relevance emerged as a significant covariate $(F(1,98)=75.78, p<.001)$.

Process analysis. Again, we ran a mediation analysis using the PROCESS script (Hayes, 2013, model 4) with 5,000 bootstrap samples and 95\% confidence intervals. In line with $\mathrm{H} 2$, this analysis revealed a significant indirect effect of temporal distance on willingness to support through psychological distance $(b=-.328,95 \%$ confidence interval $[C I]=[-.712,-.045])$. 


\section{Study 2: Field data from Kickstarter}

\subsection{Design and method}

The aim of Study 2 was to test H1a and H1b in a sample of field data from Kickstarter. To this end, we focused on real campaigns launched on Kickstarter and examined if the development stage of the product and the indicated time until delivery were related to the likelihood of the campaigns reaching their funding goals. We tracked all campaigns initiated in the categories of "Technology" and "Product Design" on Kickstarter, using only those that were based in the US, so as to have one common language among campaigns, between September $1^{\text {st }} 2015$ and October $31^{\text {st }} 2015$. To make sure that the campaigns really involved technology or product design, we singled out campaigns that did not provide a hardware product, thus excluding mislabeled campaigns that involved a service or software product. In doing so, we also ensured that the campaigns assessed in our experiments and those assessed in the field data were comparable. Our final sample comprised 961 campaigns.

To operationalize our dependent variable, funding success, we assessed whether the campaigns had reached their funding goal in a dichotomous form: $0=$ funding goal not reached, 1 $=$ funding goal reached. As an ancillary variable, we used the amount of funding the campaigns had raised (as the natural logarithm).

To operationalize our independent variables, we recruited 27 students ( $25.9 \%$ female) from a German university as coders. Each coder accessed a copy of the original website data, with the total amount pledged, the number of backers, updates, and comments set to zero. Coders were blind to the hypotheses being tested. Coders rated the same ten projects, with five failed projects (lower 25\% quartile of under-funded projects) and five very successful projects (higher 25\% quartile of over-funded projects). In addition, each coder was randomly assigned a maximum of 40 additional campaigns. 
For our first independent variable, product stage, we asked the coders to rate the campaigns in terms of their product development stage: idea stage $=1$; concept stage $=2$; prototype stage $=$ 3 ; market-ready stage $=4$. For our second independent variable, temporal distance, we measured the number of months between the campaign start and the projected delivery for the product that was published on the campaign website (as the natural logarithm).

We also followed prior work in crowdfunding and controlled for a host of other factors that are independent of the development stage or the delivery time of the product and that may also affect the success of a crowdfunding campaign (Allison et al., 2017; Anglin et al., 2018a; Davis et al., 2017; Oo et al., 2018). We summarize these variables in Appendix A.

\subsection{Results and discussion}

In line with prior best practices (Bliese, 2000; Davis et al., 2017; LeBreton and Senter, 2007), inter-rater consistency was assessed using intra-class correlation coefficients for the campaigns rated by all coders (see Appendix A). While the coders originally categorized the products featured in the campaigns into four stages (idea stage: 2 , concept stage: 41 , prototype stage: 397 , market-ready stage: 521), we decided to dichotomize this variable in the analysis with idea, concept, and prototype stages representing early-stage products and the market-ready products representing later-stage products. This procedure allowed for a more parsimonious analysis and was also consistent with the manner in which product development stage was operationalized in the experimental studies. ${ }^{5}$

\footnotetext{
${ }^{5}$ We also tested whether employing the four-category measure affects our results. The marginal effect for product stage remains qualitatively invariant in the logit model $(\beta=.10, p<.01)$ and the OLS for the $\log$ (Amount) ( $(=.827$, $p<.01)$. Full results are available upon request from the authors.
} 


\begin{tabular}{|c|c|c|c|c|c|c|c|c|}
\hline & $\begin{array}{c}\text { Contr } \\
\text { (1) } \\
\text { Campaign } \\
\text { Success - } \\
\text { Odds Ratio }\end{array}$ & $\begin{array}{c}\text { (2) } \\
\text { Campaign } \\
\text { Success - } \\
\text { Margins } \\
\end{array}$ & $\begin{array}{c}\text { (3) } \\
\text { Campaign } \\
\text { Success - } \\
\text { Odds Ratio }\end{array}$ & $\begin{array}{c}\text { (4) } \\
\text { Campaign } \\
\text { Success - } \\
\text { Margins } \\
\end{array}$ & $\begin{array}{c}\frac{\text { Ancillar }}{\text { (Dep. Var }} \\
\text { (5) } \\
\text { Amount } \\
\text { Raised (Log) }\end{array}$ & $\begin{array}{c}\frac{\text { Analysis }}{\text { Variation) }} \\
(6) \\
\text { Amount } \\
\text { Raised (Log) }\end{array}$ & 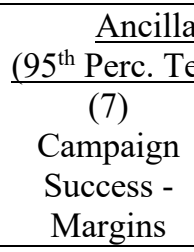 & $\begin{array}{c}\text { Analysis } \\
\text { oral Distance) } \\
(8) \\
\text { Amount } \\
\text { Raised (Log) }\end{array}$ \\
\hline Product Stage (1=Early Stage) & & & $\begin{array}{c}0.696 * * \\
(0.031)\end{array}$ & $\begin{array}{c}-0.090 * * \\
(0.031)\end{array}$ & & $\begin{array}{c}-0.792 * * \\
(0.043)\end{array}$ & $\begin{array}{c}-0.118 * * * \\
(0.006)\end{array}$ & $\begin{array}{c}-1.057 * * * \\
(0.008)\end{array}$ \\
\hline Time to Product Delivery (Log) & & & $\begin{array}{c}1.128 \\
(0.166)\end{array}$ & $\begin{array}{c}0.030 \\
(0.168)\end{array}$ & & $\begin{array}{c}0.066 \\
(0.756)\end{array}$ & $\begin{array}{c}-0.058 * * * \\
(0.000)\end{array}$ & $\begin{array}{c}-0.812 * * * \\
(0.000)\end{array}$ \\
\hline Information Usefulness & $\begin{array}{l}1.243 * * \\
(0.034)\end{array}$ & $\begin{array}{c}0.054 * * \\
(0.035)\end{array}$ & $\begin{array}{c}1.218^{*} \\
(0.052)\end{array}$ & $\begin{array}{l}0.049^{*} \\
(0.054)\end{array}$ & $\begin{array}{c}0.453 * * \\
(0.046)\end{array}$ & $\begin{array}{l}0.392^{*} \\
(0.072)\end{array}$ & $\begin{array}{l}0.050^{*} \\
(0.050)\end{array}$ & $\begin{array}{c}0.387^{*} \\
(0.074)\end{array}$ \\
\hline Aesthetic Appeal & $\begin{array}{c}1.243 * * * \\
(0.000)\end{array}$ & $\begin{array}{c}0.054 * * * \\
(0.000)\end{array}$ & $\begin{array}{c}1.253 * * * \\
(0.000)\end{array}$ & $\begin{array}{c}0.056^{* * * *} \\
(0.000)\end{array}$ & $\begin{array}{c}0.566^{* * * *} \\
(0.000)\end{array}$ & $\begin{array}{c}0.580 * * * \\
(0.000)\end{array}$ & $\begin{array}{c}0.048 * * * \\
(0.002)\end{array}$ & $\begin{array}{c}0.434 * * * \\
(0.003)\end{array}$ \\
\hline Video Quality & $\begin{array}{c}1.147 * * * \\
(0.008)\end{array}$ & $\begin{array}{c}0.034 * * * \\
(0.007)\end{array}$ & $\begin{array}{l}1.137 * * \\
(0.032)\end{array}$ & $\begin{array}{c}0.032 * * \\
(0.030)\end{array}$ & $\begin{array}{c}0.299 * * \\
(0.020)\end{array}$ & $\begin{array}{c}0.281 * * \\
(0.048)\end{array}$ & $\begin{array}{c}0.037 * * \\
(0.021)\end{array}$ & $\begin{array}{c}0.336 * * \\
(0.026)\end{array}$ \\
\hline Novelty of the Solution & $\begin{array}{c}0.970 \\
(0.420)\end{array}$ & $\begin{array}{l}-0.008 \\
(0.419)\end{array}$ & $\begin{array}{c}0.967 \\
(0.340)\end{array}$ & $\begin{array}{c}-0.008 \\
(0.339)\end{array}$ & $\begin{array}{l}-0.058 \\
(0.495)\end{array}$ & $\begin{array}{l}-0.057 \\
(0.481)\end{array}$ & $\begin{array}{c}-0.014^{*} \\
(0.081)\end{array}$ & $\begin{array}{l}-0.106 \\
(0.167)\end{array}$ \\
\hline Duration of Campaign & $\begin{array}{l}1.013 * * \\
(0.031)\end{array}$ & $\begin{array}{c}0.003 * * \\
(0.030)\end{array}$ & $\begin{array}{l}1.012^{*} \\
(0.065)\end{array}$ & $\begin{array}{l}0.003^{*} \\
(0.063)\end{array}$ & $\begin{array}{c}0.048 * * \\
(0.014)\end{array}$ & $\begin{array}{c}0.046^{* *} \\
(0.013)\end{array}$ & $\begin{array}{c}0.004 * * \\
(0.050)\end{array}$ & $\begin{array}{c}0.056^{* *} \\
(0.027)\end{array}$ \\
\hline Campaign Goal (Log) & $\begin{array}{c}0.690 * * * \\
(0.006)\end{array}$ & $\begin{array}{c}-0.092 * * * \\
(0.006)\end{array}$ & $\begin{array}{c}0.680 * * * \\
(0.002)\end{array}$ & $\begin{array}{c}-0.096 * * * \\
(0.002)\end{array}$ & $\begin{array}{l}-0.392 \\
(0.103)\end{array}$ & $\begin{array}{c}-0.377^{*} \\
(0.064)\end{array}$ & $\begin{array}{c}-0.110^{* * *} \\
(0.000)\end{array}$ & $\begin{array}{c}-0.474 * * * \\
(0.004)\end{array}$ \\
\hline Size of Team & $\begin{array}{c}1.125 \\
(0.261)\end{array}$ & $\begin{array}{c}0.029 \\
(0.261)\end{array}$ & $\begin{array}{c}1.134 \\
(0.245)\end{array}$ & $\begin{array}{c}0.031 \\
(0.245)\end{array}$ & $\begin{array}{c}0.294 \\
(0.230)\end{array}$ & $\begin{array}{c}0.311 \\
(0.216)\end{array}$ & $\begin{array}{c}0.052^{* *} \\
(0.010)\end{array}$ & $\begin{array}{c}0.487 * * * \\
(0.002)\end{array}$ \\
\hline Highest Level of Education & $\begin{array}{c}1.024 \\
(0.848)\end{array}$ & $\begin{array}{c}0.006 \\
(0.848)\end{array}$ & $\begin{array}{c}1.017 \\
(0.894)\end{array}$ & $\begin{array}{c}0.004 \\
(0.894)\end{array}$ & $\begin{array}{c}0.103 \\
(0.760)\end{array}$ & $\begin{array}{c}0.089 \\
(0.793)\end{array}$ & $\begin{array}{c}-0.069 * * \\
(0.019)\end{array}$ & $\begin{array}{c}-0.630 * \\
(0.089)\end{array}$ \\
\hline Business Skills & $\begin{array}{c}0.961 \\
(0.387)\end{array}$ & $\begin{array}{l}-0.010 \\
(0.386)\end{array}$ & $\begin{array}{c}0.977 \\
(0.658)\end{array}$ & $\begin{array}{c}-0.006 \\
(0.658)\end{array}$ & $\begin{array}{l}-0.077 \\
(0.525)\end{array}$ & $\begin{array}{l}-0.044 \\
(0.744)\end{array}$ & $\begin{array}{l}-0.001 \\
(0.962)\end{array}$ & $\begin{array}{c}0.005 \\
(0.968)\end{array}$ \\
\hline $\begin{array}{l}\text { \# Backed Crowdfunding } \\
\text { Campaigns (Log) }\end{array}$ & $\begin{array}{l}1.360 * * * \\
(0.002)\end{array}$ & $\begin{array}{c}0.077 * * * \\
(0.002)\end{array}$ & $\begin{array}{c}1.362 * * * \\
(0.003)\end{array}$ & $\begin{array}{c}0.077 * * * \\
(0.003)\end{array}$ & $\begin{array}{c}0.695 * * * \\
(0.002)\end{array}$ & $\begin{array}{c}0.704 * * * \\
(0.003)\end{array}$ & $\begin{array}{c}0.103^{* * * *} \\
(0.000)\end{array}$ & $\begin{array}{c}0.944 * * * \\
(0.000)\end{array}$ \\
\hline Minority Team member & $\begin{array}{c}1.731 * * * \\
(0.000)\end{array}$ & $\begin{array}{c}0.136 * * * \\
(0.000)\end{array}$ & $\begin{array}{c}1.761 * * * \\
(0.000)\end{array}$ & $\begin{array}{c}0.140 * * * \\
(0.000)\end{array}$ & $\begin{array}{c}1.505 * * * \\
(0.000)\end{array}$ & $\begin{array}{c}1.535 * * * \\
(0.000)\end{array}$ & $\begin{array}{c}0.146 * * * \\
(0.000)\end{array}$ & $\begin{array}{c}1.538 * * * \\
(0.001)\end{array}$ \\
\hline Female in the Team & $\begin{array}{l}1.453 * * \\
(0.045)\end{array}$ & $\begin{array}{l}0.093 * * \\
(0.045)\end{array}$ & $\begin{array}{l}1.462^{*} \\
(0.061) \\
\end{array}$ & $\begin{array}{l}0.095^{*} \\
(0.060) \\
\end{array}$ & $\begin{array}{c}0.984 \\
(0.128) \\
\end{array}$ & $\begin{array}{c}0.982 \\
(0.149) \\
\end{array}$ & $\begin{array}{c}0.004 \\
(0.879) \\
\end{array}$ & $\begin{array}{c}0.065 \\
(0.839) \\
\end{array}$ \\
\hline $\begin{array}{l}\text { Adj Count } \mathrm{R}^{2} / \text { Adj. } \mathrm{R}^{2} \\
\mathrm{P}>\mathrm{Chi}^{2} / \mathrm{F}-\text { Value } \\
\text { Observations }\end{array}$ & & & & & $\begin{array}{c}0.151 \\
0.000 \\
961\end{array}$ & $\begin{array}{c}0.156 \\
0.000 \\
961\end{array}$ & $\begin{array}{c}0.258 \\
0.000 \\
923\end{array}$ & $\begin{array}{c}0.169 \\
0.000 \\
923\end{array}$ \\
\hline
\end{tabular}

$* p<.1, * * p<.05, * * * p<.01$

Table 1: Regression antecedents to campaign success and amount raised 
Due to the binary nature of our outcome measure, we employed a logit regression to test the effect of product stage on funding success (see Table 1). In line with H1a, the results showed that campaigns featuring products in a less advanced development stage have lower odds of reaching their funding goal $(\beta=.696, p<.05)$. This marginal effect translates into a 9-percentage point reduction in the probability to reach the campaign goal. To estimate the monetary consequences of these effects, we also examined the relationship between our predictor variables and the actual amount raised by the campaign using OLS regression. When campaigns displayed products in an early development stage, they raised about 23 percent less in actual campaign contributions, providing further support for H1a (see Table 1).

Next, we examined if the temporal gap between campaign start and planned product delivery affected campaign success. Due to the skewed distribution, we operationalized temporal distance as the natural logarithm. This analysis, however, revealed that the coefficient for our measure of temporal distance was insignificant (see column 6 in Table 1). When we winsorized the distribution to include only observations up until the $95^{\text {th }}$ percentile of the distribution (column 7 and 8 in Table 1), we observe a negative effect of planned product delivery on both campaign success (marginal effect $=-.058, p<.01)$ and the amount raised $(\beta=-.812 ; p<.01)$, providing support for $\mathrm{H}^{1} \mathrm{~b}^{6}$.

In sum, the field data corroborates the findings from the experimental studies and provides support for the notion that both hypothetical and temporal distance affect campaign success and the amount of funding raised. Importantly, the results show that the effect of each dimension is significant even when the effect of the other dimension is controlled for, suggesting that

\footnotetext{
${ }^{6}$ We thank an anonymous referee for suggesting these ancillary considerations. We also corroborated this effect using a test for non-linearity following Lind and Mehlum (2010) and by employing a piece-wise curve fitting (spline) approach to allow for potential non-linearity (Royston and Sauerbrei, 2018). The lowest point is reached when the time gap is about six months, and it persists up until the nine-month mark. After this point, the confidence intervals are too wide, given the low number of observations, to draw meaningful inferences.
} 
hypothetical and temporal distance are conceptually and empirically distinct.

\section{Study 3: Psychological distance and mental simulation}

\subsection{Study 3a: Hypothetical distance}

\subsubsection{Design, participants, and procedure}

The purpose of Study 3a was to test H3a and H3b. Study 3a used a 2 (product stage: earlystage vs. market-ready) x 2 (mental simulation: outcome vs. process) between-subjects design. A total of 175 students $(51.0 \%$ female) were recruited through the participant pool of a German university. Student samples are often used in research on entrepreneurship and are considered particularly appropriate for research using experimental methods (e.g., Davis et al., 2017; Gaglio and Katz, 2001; Prandelli et al., 2016). On average, participants were 23.9 years old and 20.6\% indicated that they were relatively experienced with crowdfunding. The procedure of the study followed the procedure described in the first pretest and Study 1a.

\subsubsection{Independent variables}

Study 3a employed the Amabrush campaign. Product stage was manipulated in the same way as in the previous studies. To manipulate mental simulation, the campaign descriptions either encouraged participants to imagine the end benefits associated with using the product (i.e., outcome simulation) or the different steps that would be involved in using the product (i.e., process simulation). Participants in the outcome condition were presented with a paragraph that contained a listing of the benefits that one would gain from using Amabrush, and were encouraged to imagine these benefits. In the process condition, this paragraph was altered with detailed explanations and illustrations of the usage process. Apart from these changes, the campaigns were identical (see also the supplementary appendix). 


\subsubsection{Measures}

Willingness to support. Willingness to support was measured using the same items as in Studies $1 \mathrm{a}$ and $1 \mathrm{~b}(\alpha=.79)$.

Manipulation checks. Consistent with prior research (Escalas and Luce 2004), two different checks ensured that mental simulation had been manipulated effectively. First, we measured selfreported process simulation on one item ("While viewing the campaign, how strongly did you think about the individual steps you would go through when using the presented product?"). Second, we measured self-reported outcome simulation on another item ("While viewing the campaign, how strongly did you think about the advantages and outcomes that would result from using the proposed product?").

Covariate. Again, we measured personal relevance as a potential covariate with the same items as in Studies 1a and $1 \mathrm{~b}(\alpha=.89)$.

\subsubsection{Results}

Manipulation check. To test for differences in thought focus, we conducted within- and between-group comparisons. A within-group comparison indicated that respondents in the outcome condition generated more outcome-oriented thoughts than process-oriented thoughts $\left(M_{\text {outcome }}=5.44, M_{\text {process }}=4.51, t(87)=4.82, p<.001\right)$, while respondents in the process condition did not differ in terms of outcome- vs. process-focused thinking $\left(M_{\text {outcome }}=5.51, M_{\text {process }}=5.25\right.$, $t(86)=.60, p=.548)$. A between-group comparison revealed that respondents in the process condition reported higher levels of process-focused thinking than did respondents in the outcome condition $\left(M_{\text {outcome }}=4.51, M_{\text {process }}=5.25, F(1,173)=9.95, p=.002\right)$. These findings indicate that participants in the outcome conditions focused more strongly on the outcomes associated with using the product, while participants in the process conditions focused on both the process and the outcomes. These findings are in line with previous research, which finds that thinking about 
the process of using a product also triggers thoughts about the outcome of that process, while focusing on outcomes does not require thinking about the process that is necessary to achieve them (Escalas and Luce, 2003; 2004).

Willingness to contribute. A $2 \times 2$ ANCOVA with willingness to contribute as the dependent variable and personal relevance as a covariate revealed a significant main effect for product stage $(F(1,170)=19.53, p=.006)$, an insignificant main effect for mental simulation $(F(1,170)=1.75, p=.188)$, and a significant interaction $(F(1,170)=7.70, p=.006)$. Personal relevance emerged as a significant covariate $(F(1,170)=93.76, p<.001)$. To follow up on the interaction effect, we performed two planned contrasts (see also Figure 3).

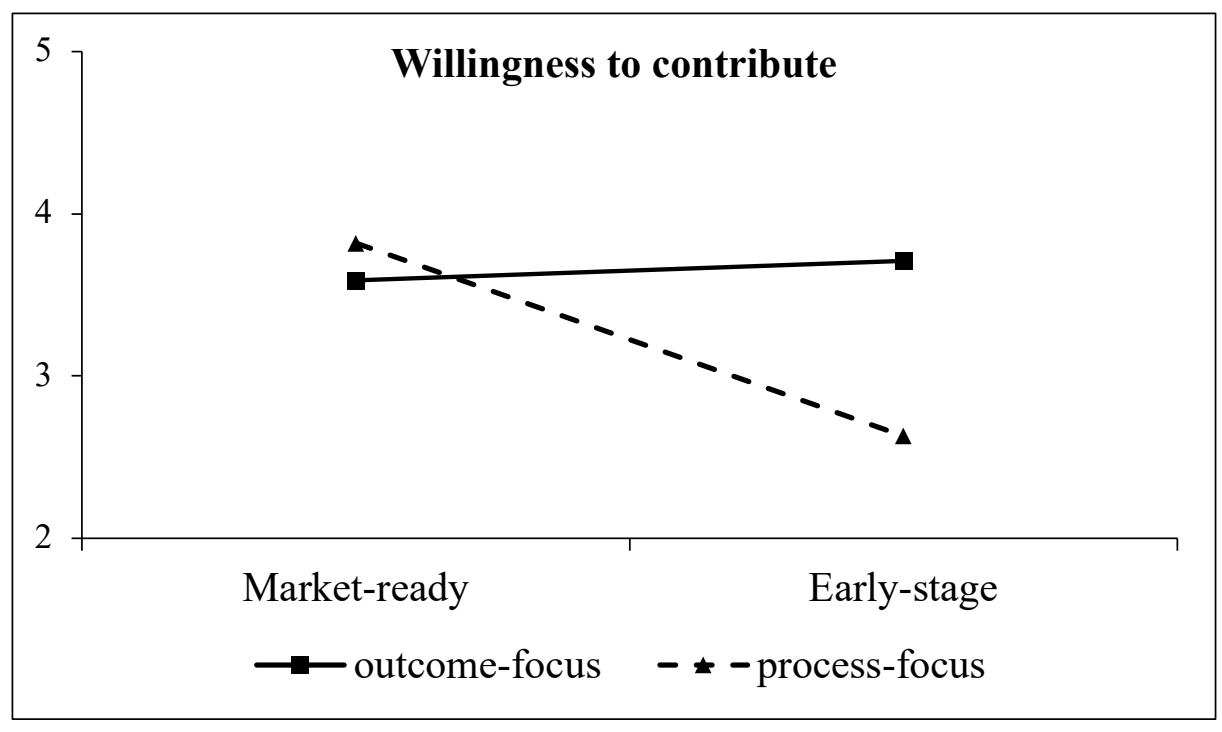

Figure 3: Results of Study $3 a$

Consistent with H3a, participants who had been exposed to an early-stage product reported a higher willingness to contribute when they engaged in outcome simulation than when they engaged in process simulation $\left(M_{\text {outcome }}=3.71, M_{\text {process }}=2.63, F(1,170)=9.20, p=.003\right)$. When, however, participants evaluated a product in a more advanced development stage, willingness to contribute did not differ across the two types of mental simulation $\left(M_{\text {outcome }}=3.59, M_{\text {process }}=\right.$ $3.82, F(1,170)=.42, p=.520)$. These results indicate that $\mathrm{H} 3 \mathrm{~b}$ is not supported and that mental 
simulation does not affect how potential backers evaluate market-ready products. These findings are discussed in greater detail in the general discussion.

\subsection{Study $3 b$}

\subsubsection{Design, participants, and procedure}

Study $3 \mathrm{~b}$ aimed to test $\mathrm{H} 3 \mathrm{a}$ and $\mathrm{H} 3 \mathrm{~b}$ and used a 2 (temporal distance: near future vs. distant future) x 2 (mental simulation: outcome vs. process) between-subjects design. A total of 140 students (36\% female) recruited from a German university voluntarily completed the study online. On average, participants were 21.4 years old and $9.2 \%$ indicated that they were relatively experienced with crowdfunding. Except for the manipulation of temporal distance, the procedure of Study $3 \mathrm{~b}$ was identical to Study $3 \mathrm{a}$.

\subsubsection{Independent variables}

Study 3b, too, used the Amabrush campaign. The first manipulation focused on the time that was needed to deliver the product to customers. As in Study 1b, participants were informed that the product would be delivered within 30 days (near future) or nine months (distant future) after the successful completion of the campaign. The second manipulation focused on mental simulation and was identical to Study 3a.

\subsubsection{Measures}

All measures were identical to Study 3a (willingness to support: $\alpha=.91$; personal relevance: $\alpha=.86$ ).

\subsubsection{Results}

Manipulation check. Similar to Study 3a, respondents in the outcome conditions reported higher outcome focus than process focus $\left(M_{\text {outcome }}=4.51, M_{\text {process }}=3.84, t(69)=2.83, p=.006\right)$, while respondents in the process condition did not differ in terms of their focus $\left(M_{\text {outcome }}=4.56\right.$, 
$\left.M_{\text {process }}=4.63, t(69)=-.20, p=.845\right)$. A between-group comparison showed that respondents in the process conditions reported higher levels of process-focused thinking relative to respondents in the outcome conditions $\left(M_{\text {outcome }}=3.84, M_{\text {process }}=4.63, F(1,138)=10.24, p=.002\right)$. Hence, the manipulation of mental simulation was successful.

Willingness to support. A $2 \times 2$ ANCOVA with willingness to contribute as the dependent variable and personal relevance as a covariate revealed an insignificant main effect for temporal distance $(F(1,135)=.001, p=.971)$, an insignificant main effect for mental simulation $(F(1,135)$ $=1.82, p=.179)$, and a significant interaction $(F(1,135)=6.40, p=.013)$. Again, relevance was a significant covariate $(F(1,135)=81.25, p<.001)$. To follow up on these effects, we performed two planned contrasts (see also Figure 4).

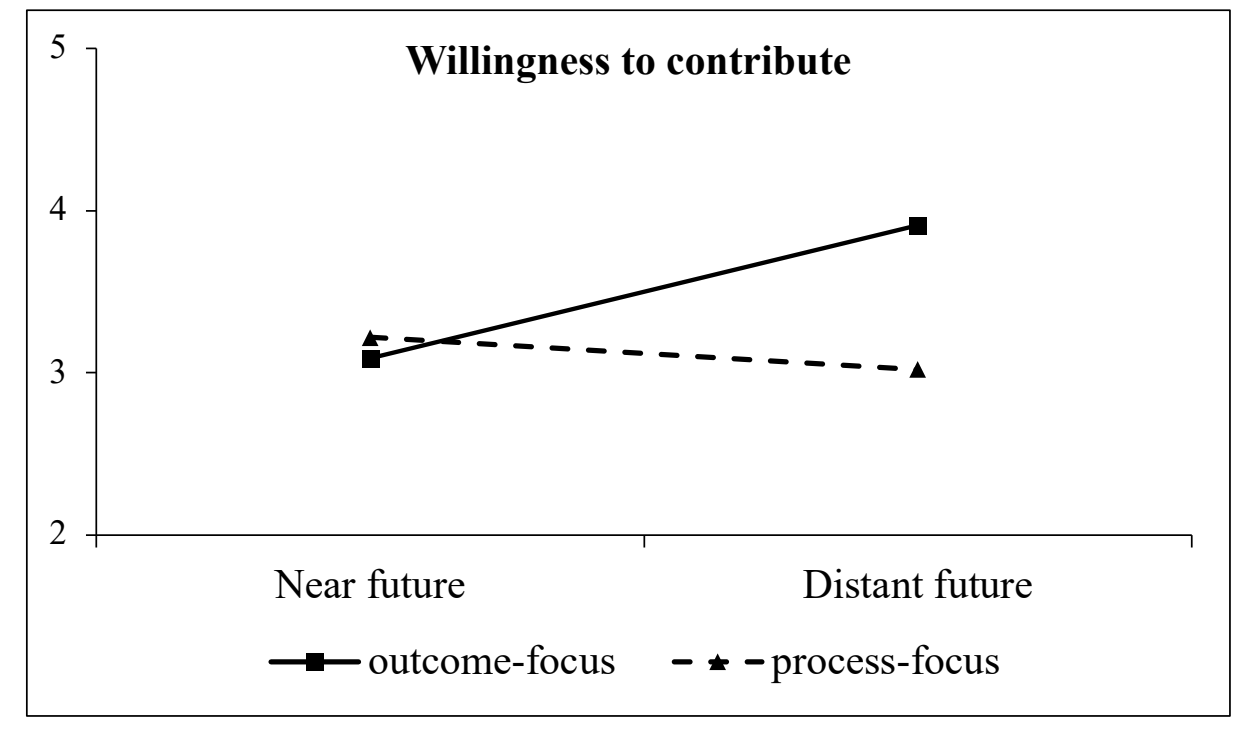

Figure 4: Results of Study $3 b$

When participants were exposed to a campaign that would deliver the product in the distant future, they reported a higher willingness to contribute when they were encouraged to engage in outcome simulation than when they were encouraged to engage in process simulation $\left(M_{\text {outcome }}=\right.$ $\left.3.91, M_{\text {process }}=3.02, F(1,136)=5.33, p=.022\right)$. When, however, they evaluated a campaign that 
would deliver the product in the near future, willingness to contribute did not differ across the two types of mental simulation $\left(M_{\text {outcome }}=3.09, M_{\text {process }}=3.22, F(1,136)=.126, p=.723\right)$. Similar to Study 3a, these results support H3a but fail to provide support for H3b.

\section{Discussion}

In this research, we examined how potential supporters form mental representations of products featured in crowdfunding campaigns, and how the abstractness of these representations affects individual funding decisions and collective campaign performance. To this end, we conducted four experiments and analyzed a sample of field data from Kickstarter. Studies 1a and $1 \mathrm{~b}$ showed that backers are less likely to support campaigns that feature products that are in an early stage of the development process or that indicate a long delivery time, and that these effects are determined by the psychological distance they experienced in response to the campaigns. Study 2 focused on data from Kickstarter and found that these effects also affected the performance of real-life campaigns. Campaigns that displayed products in a less advanced development stage or indicated a longer delivery time had a lower likelihood of reaching their funding goals than campaigns that featured products in a more advanced development stage or delivered the product in less time. Finally, Studies $3 \mathrm{a}$ and $3 \mathrm{~b}$ examined how mental simulation affects campaign evaluations. Backers who evaluated psychologically more distant campaigns responded more positively when they engaged in outcome simulation than they did when they engaged in process stimulation. In contrast, backers who evaluated psychologically less distant campaigns did not respond differently to different kinds of mental simulation.

Collectively, these findings point to the role of psychological distance and mental representations in shaping the performance of crowdfunding campaigns. While our field study is correlational in nature and does not allow us to draw causal inferences, our experimental studies 
do allow for such inferences. The fact that the results of the experimental studies align with those of the field study increases our confidence that psychological distance does indeed matter for the performance of real-life campaigns. All findings are also summarized in Appendix B.

\subsection{Theoretical implications}

With our findings, we make three contributions to the literature on crowdfunding as well as to the literature on entrepreneurial resource acquisition.

First, a rich research tradition in entrepreneurship highlights the intricate nature of entrepreneurial resource acquisition and the uncertainties that formal and informal investors face in their funding decisions (Davis et al., 2017; Martens et al., 2007; Parhankangas and Ehrlich, 2014; Scheaf et al., 2018). Our findings contribute to this stream of research by extending the understanding of the determinants that affect an entrepreneur's ability to acquire resources for his or her venture. We show that two campaign characteristics - a product's development stage and the time to delivery - affect resource contributions by eliciting different degrees of psychological distance. Thus, we highlight that resource contributions in crowdfunding are a function of psychological distance and find that campaigns that trigger higher degrees of distance are less effective on the individual as well as the aggregate level. Prior research applying CLT to entrepreneurship has focused on the perspective of the entrepreneur and has examined how psychological distance affects the evaluation of entrepreneurial opportunities (Tumasjan et al., 2013). To the best of our knowledge, the present study is the first to demonstrate the relevance of psychological distance in the resource acquisition process.

Second, our findings contribute to the emerging stream of research studying the role of communication in entrepreneurial resource mobilization (Anglin et al., 2018a; van Werven et al., 2015; 2019). Previous studies on entrepreneurial fundraising have mostly focused on links between product-, entrepreneur-, or venture-level characteristics and the acquisition of financial 
resources, including the effects of founder credibility (Islam et al., 2018; Plummer et al., 2016), start-up team characteristics (Franke, 2006; Oo et al., 2018), product innovativeness (Chan and Parhankangas, 2017), and entrepreneurial passion (Davis et al., 2017; Jiang et al., 2019). Only recently has research begun to address the important role that language and storytelling play for resource mobilization in early-stage ventures. For instance, Täuscher et al. (2020) show that campaigns should invoke narratives that deviate from prototypical narratives to raise campaign awareness and to effectively raise funds. Our study extends this work by focusing on the link between the type of communication used in a campaign and the acquisition of financial resources. Showing that the inhibiting effects of psychological distance may be overcome by outcome simulation as a specific type of mental simulation, our research indicates that an entrepreneur's communicative efforts should align with the mental representations of potential supporters.

Third, our study expands our knowledge on how "imagined futures" can be communicated in different phases of venture development (Garud et al., 2010: 763). Prior work has highlighted how cognitive processes can affect the early stages of idea formation and the recognition of business ideas, focusing on future-oriented cognitive processes such as analogical reasoning (Grégoire et al., 2010), imaginativeness (Kier and McMullen, 2018), and prospective thinking (Frederiks et al., 2019). Yet, existing studies rarely specify which instruments entrepreneurs should employ to positively shape the assessments of external parties of their venture ideas and/or how the effectiveness of specific instruments may change as a venture advances and a new product emerges in a more concrete form.

In this respect, our results highlight that another future-oriented cognitive process, mental simulation, may help entrepreneurs in communicating their vision and also suggest contingencies for effective entrepreneurial communication (Soublière and Gehman, 2019). In the early phases of a campaign's development, interactions often focus on community building with individuals 
who have high domain-specific knowledge (Murray et al. 2020). These individuals are likely to understand the benefits that will accrue from the proposed product, as a result of which a processoriented focus may be more effective (for example, when requesting feedback on a prototype). As the venture advances, it may start to attract the attention of more general potential customers. While these individuals may help to increase the viability of a new venture's vision (Matthews et al., 2018), they may be more effectively persuaded when the campaign pages feature a more outcome-oriented approach. Hence, our findings contribute by delineating how different types of potential customers may form mental representations of entrepreneurial ideas at different stages of a new venture's development (by pointing to the role of psychological distance and different construal levels) and by laying out a framework for effectively communicating these visions (by pointing to the role of mental simulations).

\subsection{Practical implications}

Our research has important practical implications, showing that two campaign characteristics - product stage and time to delivery - determine psychological distance, which, in turn, affect the effectiveness of a campaign. A naïve conclusion from this finding is that entrepreneurs should launch crowdfunding campaigns only after they have finalized the product development process and/or are able to deliver the product in the near future. A more nuanced interpretation is that entrepreneurs need to match their messages to the informational needs that are triggered by their campaigns. Campaigns that display products in early development stages or that indicate that it will take a long time to deliver are prone to benefit-related uncertainties. As our findings show, encouraging potential funders to engage in outcome simulation seems an

effective strategy to enhance performance. In our study, we triggered outcome simulation through modifying the campaign description and encouraging participants to imagine the benefits that 
would accrue from using the product. Even though this modification was straightforward to implement, it was effective in increasing willingness to contribute to a campaign that was still in an early phase or would deliver the proposed product in the distant future. ${ }^{7}$

Two real-life examples from Kickstarter illustrate how language is used by campaign creators to trigger either outcome- or process-focused mental simulation. The description of the Micro, a consumer 3D-printer, is reminiscent of outcome-focused mental simulation: "Bring your ideas to life, turn them into businesses, educate, learn, personalize products, make toys, make jewelry, start a curriculum, run a modern workshop, and unleash your creativity." In contrast, the description of a similar product, the B-Creative 3D Printer, is more reminiscent of processfocused simulation: "The B-Creative Printer comes with $0.05 \mathrm{~mm}$ layer printing support letting you print any object with high accuracy and finish. With the BL100 support and $0.05 \mathrm{~mm}-0.4 \mathrm{~mm}$ print layer, you can choose from a variety of print options to modify your print design." It is impossible to assess in hindsight to what extent the performance of these ventures was affected by campaign descriptions designed to elicit different kinds of mental simulation. However, these two campaigns provide good examples of how the language used in campaign descriptions may address different criteria that backers rely on when evaluating a campaign: the desirability or the feasibility of using the proposed product.

On a more general level, our findings have implications for entrepreneurship education and support programs such as incubators or accelerators. As detailed at the end of the previous section, understanding how investors or potential customers form mental representations of a new

\footnotetext{
${ }^{7}$ Interestingly, Kickstarter altered their campaign guidelines for creators in June 2019, updating a special section dedicated to the correct display of a product's development. These guidelines directly address two subjects of this research by stating that "prototype demonstration should reflect a product's current state and should not include any CGI (computer generated images) or specific effects to demonstrate functionality that does not yet exist. If a project requires software and hardware integration, creators are required to show that functionality and any dependency clearly, or disclose that it has not yet been developed." Both of these guidelines point to functional and temporal uncertainties that may be associated with crowdfunding campaigns and that may undermine the likelihood of reaching campaign goals (https://web.archive.org/web/20190615214325/http://kickstarter.com/rules).
} 
venture idea and how potential uncertainties can be alleviated through processes of mental simulation may allow emerging entrepreneurs to enhance the quality of their pitch narratives and to effectively communicate the desirability of their visions for the future.

\subsection{Limitations and future research}

Naturally, our research has limitations that call for future research. First, Studies $3 \mathrm{a}$ and $3 \mathrm{~b}$ showed that responses to psychologically distant campaigns were improved through outcome simulation, but that responses to psychologically close campaigns were not affected by different kinds of mental simulation. Arguably, these results may be attributed to how participants responded to our experimental instructions. Across both studies, we found that participants in the outcome conditions focused more strongly on outcome-related thoughts, while participants in the process conditions focused on both process- and outcome-related thoughts. Although these findings align with prior research (Escalas and Luce, 2003; 2004), this dual-thought focus may have affected the results. If psychologically less distant campaigns indeed trigger feasibility concerns, then dividing one's attention between process- and outcome-related thoughts may be a relatively ineffective strategy to resolve those concerns. Future research might investigate more fully how backers' attention can be focused on the process, while shifting attention away from the outcome at the same time.

Second, we focused only on hypothetical and temporal distance as we felt that these two dimensions are inherent to reward-based crowdfunding. That is, as crowdfunding campaigns focus on products that have not been developed yet and may only be realized at a distant point in the future, notions of hypothetical and temporal distance are likely very salient for potential backers. Nonetheless, CLT has also identified spatial and social distance as determinants of psychological distance (Trope and Liberman 2010). Arguably, these two dimensions could also 
affect the performance of crowdfunding campaigns. For instance, backers may be more (vs. less) likely to contribute to campaigns when the founders are located spatially close (vs. distant) (Burtch et al., 2014; Mollick, 2014) and/or when they feel socially close to the founders (vs. distant) due to similarities (vs. differences) in background. As a case in point, past studies have revealed that crowdfunding entrepreneurs benefit from leveraging their existing social ties, especially in the early phases of a new campaign (e.g. Agrawal et al. 2011; Skirnevskiy et al. 2017). However, these studies have not used CLT as their theoretical vantage point, suggesting that future research may examine more systematically how spatial and social distance contribute to a more general sense of psychological distance.

Third, in terms of generalizability, our research focused on one particular type of crowdfunding (i.e., reward-based) and one particular category within that type (i.e., hardware products). This limitation raises the question of whether our findings generalize to other types of crowdfunding and/or categories. For instance, it may be of interest to examine the effects of psychological distance in the context of campaigns promoting products that are digital in nature, such as video games, movies, and software. Because they lack a physical form, digital products are likely to feel more abstract than the hardware products that were the focus of this research (Atasoy and Morewedge 2018; Laroche et al., 2001). Arguably, campaigns focused on such products will always trigger high levels of distance - even when they are in an advanced development stage or will be finalized in the near future. Put differently, the impact of development stage and time to delivery on the psychological distance experienced by potential supporters may be moderated by the kind of product being promoted.

Fourth, future studies may also examine if our findings extend to social crowdfunding platforms such as Kiva. On these platforms, supporters can extend small loans to low-income entrepreneurs and students to help them realize a specific project (Short and Anglin, 2019). As 
loans are repaid without interest, supporters need to consider both social (the desire to fund a worthy cause) and economic motives (the likelihood of being repaid) in their funding decisions (Berns et al., 2018). The impact of these motives may be contingent on the psychological distance elicited by the campaign. Because of their abstract nature, values and moral beliefs are more prominent when considering psychologically distant decisions (Eyal and Liberman, 2012; Rixom and Mishra, 2014), whereas monetary considerations are more concrete and thus play a relatively stronger role for psychologically near decisions (Bornemann and Homburg, 2011). Hence, we would suspect that campaigns that appear more psychologically distant will benefit more strongly from campaign language emphasizing values and moral principles, whereas campaigns with more immediate goals should emphasize how the individual contributions will be put to use and benefit communities. In sum, while psychological distance may also play a role in social crowdfunding, the specific mechanisms through which distance affects funding decisions there may differ from the ones that we examined in this research.

Finally, while we focused on psychological distance as a mediating mechanism, it is possible that additional theoretical mechanisms have shaped our findings. Future research may focus on the role of psychological ownership in the context of crowdfunding decisions. Psychological ownership describes the degree to which individuals consider an object, such as a product, as "theirs" (Pierce et al., 2003). Developing feelings of ownership for a product does not require having legal ownership of the product. Instead, past research has found that merely touching a product, or imagining using or consuming one, is sufficient for feelings of ownership to emerge (Peck and Shu, 2009; Peck et al., 2013). In a crowdfunding context, these findings may not only imply that supporters of crowdfunding campaigns can develop psychological ownership of products that they cannot experience directly and that do not yet exist; they may also help to explain how development stage and time to delivery affect funding decisions and campaign 
performance. Because supporters may find it easier to imagine consuming a product that is in a more advanced development stage, and/or that will be realized in a short time span, they may be more likely to develop feelings of ownership for such a product. As a result, they may be more likely to pledge their funds to the campaign in order to obtain actual ownership of the product. Nevertheless, the effects of psychological distance and those of psychological ownership are not mutually exclusive, and both may shape funding decisions concurrently.

\section{Conclusion}

Our research investigates how potential backers form mental representations of products featured in reward-based crowdfunding campaigns and how these representations affect campaign performance. For scholars, our research introduces psychological distance as an important factor in understanding crowdfunding performance and links psychological distance to campaign characteristics. For practitioners, especially entrepreneurs, our research highlights the role of mental simulation in shaping supporters' mental representations of crowdfunding campaigns and their funding decisions. Going forward, our findings suggest that CLT and mental simulation might be applied more broadly in an entrepreneurial financing context and provide new insights on how entrepreneurs can persuade professional and informal investors to supply financial resources (e.g., Chen et al., 2009; Pollack et al., 2012; van Balen et al., 2019). As the success of new ventures often depends on the ability of an entrepreneur to convince funders to support a product that is yet to be developed, we hope that our study will encourage more research along these lines. 


\section{References}

Agrawal, A. K., Catalini, C., Goldfarb, A., 2011. The geography of crowdfunding. National bureau of economic research. doi: 10.3386/w16820

Alexander, D.L., Lynch, J.G., Wang, Q., 2008. As time goes by: Do cold feet follow warm intentions for really new versus incrementally new products? Journal of Marketing Research 45 (3), 307-319. doi:10.1509/jmkr.45.3.307.

Atasoy, O., Morewedge, C.K., 2017. Digital goods are valued less than physical goods. Journal of Consumer Research, 44 (6), 1343-1357. https://doi.org/10.1093/jcr/ucx102

Allison, T.H., Davis, B.C., Webb, J.W., Short, J.C., 2017. Persuasion in crowdfunding: An elaboration likelihood model of crowdfunding performance. Journal of Business Venturing 32 (6), 707-725. doi:10.1016/j.jbusvent.2017.09.002.

Anglin, A.H., Short, J.C., Drover, W., Stevenson, R.M., McKenny, A.F., Allison, T.H., 2018a. The power of positivity?: The influence of positive psychological capital language on crowdfunding performance. Journal of Business Venturing 33 (4), 470-492. doi:10.1016/j.jbusvent.2018.03.003.

Anglin, A.H., Wolfe, M.T., Short, J.C., McKenny, A.F., Pidduck, R.J., 2018b. Narcissistic rhetoric and crowdfunding performance: A social role theory perspective. Journal of Business Venturing 33 (6), 780-812. doi:10.1016/j.jbusvent.2018.04.004.

Belleflamme, P., Lambert, T., Schwienbacher, A., 2013. Individual crowdfunding practices. Venture Capital 15 (4), 313-333. doi:10.1080/13691066.2013.785151.

Berns, J.P., Figueroa-Armijos, M., da Motta Veiga, S.P., Dunne, T.C., 2018. Dynamics of lending-based prosocial crowdfunding: Using a social responsibility lens. Journal of Business Ethics, 1-17. doi:10.1007/s10551-018-3932-0.

Bliese, P., 2000. Within-group agreement, non-independence, and reliability: Implications for 
data aggregation and analysis, in: Klein, K.J., Kozlowski, S.W.J. (Eds.), Multilevel theory, research, and methods in organizations. Foundations, extensions, and new directions. Frontiers of industrial and organizational psychology. Jossey-Bass, San Francisco, Great Britain, pp. 349-381.

Bornemann, T., Homburg, C., 2011. Psychological distance and the dual role of price. Journal of Consumer Research 38 (3), 490-504. doi: 10.1086/659874.

Burtch, G., Ghose, A., \& Wattal, S., 2014. Cultural differences and geography as determinants of online prosocial lending. MIS Quarterly 38 (3), 773-794. doi:10.2307/26634995

Castaño, R., Sujan, M., Kacker, M., Sujan, H., 2008. Managing consumer uncertainty in the adoption of new products: Temporal distance and mental simulation. Journal of Marketing Research 45 (3), 320-336. doi:10.1509/jmkr.45.3.320.

Chan, C.S.R., Parhankangas, A., 2017. Crowdfunding innovative ideas: How incremental and radical innovativeness influence funding outcomes. Entrepreneurship Theory and Practice 41 (2), 237-263. doi:10.1111/etap.12268.

Chen, X.-P., Yao, X., Kotha, S., 2009. Entrepreneur passion and preparedness in business plan presentations: A persuasion analysis of venture capitalists' funding decisions. Academy of Management Journal 52 (1), 199-214. doi:10.5465/amj.2009.36462018.

Cholakova, M., Clarysse, B., 2015. Does the possibility to make equity investments in crowdfunding projects crowd out reward-based investments? Entrepreneurship Theory and Practice 39 (1), 145-172. doi:10.1111/etap.12139.

Ciuchta, M.P., Letwin, C., Stevenson, R.M., McMahon, S.R., 2016. Regulatory focus and information cues in a crowdfunding context. Applied Psychology, 65 (3), 490-514. doi: 10.1111/apps.12063.

Colombo, M.G., Franzoni, C., Rossi-Lamastra, C., 2015. Internal social capital and the attraction 
of early contributions in crowdfunding. Entrepreneurship Theory and Practice 39 (1), 75-100. doi:10.1111/etap.12118.

Davidsson, P., 2015. Entrepreneurial opportunities and the entrepreneurship nexus: A reconceptualization. Journal of Business Venturing, 30 (5), 674-695. doi:10.1016/j.jbusvent.2015.01.002

Davis, B.C., Hmieleski, K.M., Webb, J.W., Coombs, J.E., 2017. Funders' positive affective reactions to entrepreneurs' crowdfunding pitches: The influence of perceived product creativity and entrepreneurial passion. Journal of Business Venturing 32 (1), 90-106. doi:10.1016/j.jbusvent.2016.10.006.

Dhar, R., Kim, E., 2007. Seeing the forest or the trees: Implications of construal level theory for consumer choice. Journal of Consumer Psychology 17 (2), 96-100. doi:10.1016/s10577408(07)70014-1.

Dimov, D., 2010. Nascent entrepreneurs and venture emergence: Opportunity confidence, human capital, and early planning. Journal of Management Studies, 47 (6), 1123-1153. doi:10.1111/j.1467-6486.2009.00874.x.

Escalas, J.E., Luce, M.F., 2003. Process versus outcome thought focus and advertising. Journal of Consumer Psychology 13 (3), 246-254. doi:10.1207/S15327663JCP1303_06.

Escalas, J.E., Luce, M.F., 2004. Understanding the effects of process-focused versus outcomefocused thought in response to advertising. Journal of Consumer Research 31 (2), 274-285. doi: $10.1086 / 422107$.

Eyal, T., Liberman, N., 2012. Morality and psychological distance: A construal level theory perspective. In: M. Mikulincer, P. R. Shaver (Eds.), The social psychology of morality: Exploring the causes of good and evil, 185-202. doi: 10.1037/13091-010. 
Fisher, G., Kuratko, D.F., Bloodgood, J.M., Hornsby, J.S., 2017. Legitimate to whom? The challenge of audience diversity and new venture legitimacy. Journal of Business Venturing 32 (1), 52-71. doi:10.1016/j.jbusvent.2016.10.005.

Franke, N., Gruber, M., Harhoff, D., Henkel, J., 2006. What you are is what you like: similarity biases in venture capitalists' evaluations of start-up teams. Journal of Business Venturing, 21 (6), 802-826. doi:10.1016/j.jbusvent.2005.07.001.

Frederiks, A. J., Englis, B. G., Ehrenhard, M. L., Groen, A. J. (2019). Entrepreneurial cognition and the quality of new venture ideas: An experimental approach to comparing future-oriented cognitive processes. Journal of Business Venturing 34 (2), 327-347. doi: 10.1016/j.jbusvent.2018.05.007.

Fundable, 2014. Crowdfunding Statistics. https://www.fundable.com/crowdfunding101/crowdfunding-statistics.

Gaglio, C.M., Katz, J.A., 2001. The Psychological Basis of Opportunity Identification:

Entrepreneurial Alertness. Small Business Economics 16 (2), 95-111. doi:10.1023/A:1011132102464.

Garud, R., Kumaraswamy, A., Karnøe, P., 2010. Path dependence or path creation? Journal of Management Studies, 47(4), 760-774. doi: 10.1111/j.1467-6486.2009.00914.x.

Grégoire, D.A., Barr, P.S., Shepherd, D.A., 2010. Cognitive processes of opportunity recognition: The role of structural alignment. Organization Science, 21 (2), 413-431. doi: 10.1287/orsc. 1090.0462 .

Hamilton, R.W., Thompson, D.V., 2007. Is there a substitute for direct experience?: Comparing consumers' preferences after direct and indirect product experiences. Journal of Consumer Research 34 (4), 546-555. doi:10.1086/520073.

Hayes, A.F., 2013. Introduction to mediation, moderation, and conditional process analysis: A 
regression-based approach. Guilford Press, New York.

Henderson, M. D., Wakslak, C. J., Fujita, K., Rohrbach, J. 2011. Construal level theory and spatial distance. Social Psychology 42, 165-173. https://doi.org/10.1027/1864-9335/a000060

Hoeffler, S., 2003. Measuring preferences for really new products. Journal of Marketing Research 40 (4), 406-420. doi:10.1509/jmkr.40.4.406.19394.

Huang, N., Burtch, G., Hong, Y., Polman, E., 2016. Effects of multiple psychological distances on construal and consumer evaluation: A field study of online reviews. Journal of Consumer Psychology 26 (4), 474-482. https://doi.org/10.1016/j.jcps.2016.03.001

Im, S., Workman, J., P., 2004. Market orientation, creativity, and new product performance in high-technology firms. Journal of Marketing 68 (2), 114-132. doi: 10.1509/jmkg.68.2.114.27788

Islam, M., Fremeth, A., Marcus, A., 2018. Signaling by early stage startups: US government research grants and venture capital funding. Journal of Business Venturing, 33 (1), 35-51. doi:10.1016/j.jbusvent.2017.10.001.

Jiang, L., Yin, D., Liu, D., 2019. Can joy buy you money? The impact of the strength, duration, and phases of an entrepreneur's peak displayed joy on funding performance. Academy of Management Journal, (forthcoming). doi:10.5465/amj.2017.1423.

Kickstarter, 2019. https://www.kickstarter.com/help/stats?ref=footer.

Kier, A.S., McMullen, J.S., (2018). Entrepreneurial imaginativeness in new venture ideation. Academy of Management Journal, 61 (6), 2265-2295. doi:10.5465/amj.2017.0395.

Kim, K., Zhang, M., Li, X., 2008. Effects of temporal and social distance on consumer evaluations. Journal of Consumer Research 35 (4), 706-713. doi:10.1086/592131.

Krishnamurthy, P., Sujan, M., 1999. Retrospection versus anticipation: The role of the ad under retrospective and anticipatory self-referencing. Journal of Consumer Research 26 (1), 55-69. 
doi:10.1086/209550.

Laroche, M., Bergeron, J., Goutaland, C., 2001. A three-dimensional scale of intangibility. Journal of Service Research, 4(1), 26-38. doi:10.1177/109467050141003

LeBreton, J.M., Senter, J.L., 2007. Answers to 20 Questions About Interrater Reliability and Interrater Agreement. Organizational Research Methods 11 (4), 815-852. doi: $10.1177 / 1094428106296642$.

Li, J.J., Chen, X.-P., Kotha, S., Fisher, G., 2017. Catching fire and spreading it: A glimpse into displayed entrepreneurial passion in crowdfunding campaigns. Journal of Applied Psychology 102 (7), 1075-1090. doi:10.1037/ap10000217.

Liberman, N., Trope, Y., 1998. The role of feasibility and desirability considerations in near and distant future decisions: A test of temporal construal theory. Journal of Personality and Social Psychology 75 (1), 5-18. doi:10.1037/0022-3514.75.1.5.

Liberman, N., Trope, Y., 2014. Traversing psychological distance. Trends In Cognitive Sciences 18 (7), 364-369.

Lind, J.T., Mehlum, H., 2010. With or without u? The appropriate test for a u-shaped relationship. Oxford Bulletin of Economics and Statistics 72 (1), 109-118. doi: 10.1111/j.1468-0084.2009.00569.x

Manning, S., Bejarano, T. A. (2017). Convincing the crowd: Entrepreneurial storytelling in crowdfunding campaigns. Strategic Organization 15 (2), 194-219.

https://doi.org/10.1177/1476127016648500

Marelli, A., Ordanini A., 2016. What makes crowdfunding projects successful 'before' and 'during' the campaign? Crowdfunding in Europe. Springer, Cham. doi:10.1007/978-3-31918017-5_12.

Martens, M.L., Jennings, J.E., Jennings, P.D., 2007. Do the stories they tell get them the money 
they need? The role of entrepreneurial narratives in resource acquisition. Academy of Management Journal, 50 (5), 1107-1132. doi:10.5465/AMJ.2007.27169488.

Matthews, R.S., Chalmers, D.M., Fraser, S.S., 2018. The intersection of entrepreneurship and selling: An interdisciplinary review, framework, and future research agenda. Journal of Business Venturing 33 (6), 691-719. doi:10.1016/j.jbusvent.2018.04.008.

Mollick, E., 2014. The dynamics of crowdfunding: An exploratory study. Journal of Business Venturing 29 (1), 1-16. doi:10.1016/j.jbusvent.2013.06.005.

Mollick, E.R., Kuppuswamy, V., 2014. After the campaign: Outcomes of crowdfunding. UNC Kenan-Flagler Research Paper, (2376997). doi:10.2139/ssrn.2376997

Mollick, E., Nanda, R., 2016. Wisdom or Madness?: Comparing crowds with expert evaluation in funding the arts. Management Science 62 (6), 1533-1553. doi:10.1287/mnsc.2015.2207.

Murray, A., Kotha, S., Fisher, G., 2020. Community-based resource mobilization: How entrepreneurs acquire resources from distributed non-professionals via crowdfunding. Organization Science. (in press). https://doi.org/10.1287/orsc.2019.1339

Oo, P.P., Allison, T.H., Sahaym, A., Juasrikul, S., 2018. User entrepreneurs' multiple identities and crowdfunding performance: Effects through product innovativeness, perceived passion, and need similarity. Journal of Business Venturing. doi:10.1016/j.jbusvent.2018.08.005.

Parhankangas, A., Ehrlich, M., 2014. How entrepreneurs seduce business angels: An impression management approach. Journal of Business Venturing, 29 (4), 543-564. doi:10.1016/j.jbusvent.2013.08.001.

Parhankangas, A., Renko, M., 2017. Linguistic style and crowdfunding success among social and commercial entrepreneurs. Journal of Business Venturing 32 (2), 215-236. doi:10.1016/j.jbusvent.2016.11.001.

Peck, J., Shu, S.B., 2009. The effect of mere touch on perceived ownership. Journal of Consumer 
Research, 36(3), 434-447. doi:10.1086/598614.

Peck, J., Barger, V., Luangrath, A., 2013. In search of a surrogate for touch: The effect of haptic imagery on perceived ownership. Journal of Consumer Psychology, 23 (2), 189-196. doi:10.1016/j.jcps.2012.09.001.

Pierce, J.L., Kostova, T., Dirks, K.T., 2003. The state of psychological ownership: Integrating and extending a century of research. Review of General Psychology, 7, 84-107. doi:10.1037/1089-2680.7.1.84.

Pollack, J.M., Rutherford, M.W., Nagy, B.G., 2012. Preparedness and cognitive legitimacy as antecedents of new venture funding in televised business pitches. Entrepreneurship Theory and Practice 36 (5), 915-939. doi:10.1111/j.1540-6520.2012.00531.x.

Plummer, L.A., Allison, T.H., Connelly, B.L., 2016. Better together? Signaling interactions in new venture pursuit of initial external capital. Academy of Management Journal, 59 (5), 1585 1604. doi:10.5465/amj.2013.0100.

Prandelli, E., Pasquini, M., Verona, G., 2016. In user's shoes: An experimental design on the role of perspective taking in discovering entrepreneurial opportunities. Journal of Business Venturing 31 (3), 287-301. doi:10.1016/j.jbusvent.2016.02.001.

Rixom, J., Mishra, H., 2014. Ethical ends: Effect of abstract mindsets in ethical decisions for the greater social good. Organizational Behavior and Human Decision Processes, 124 (2), 110121. doi: 10.1016/j.obhdp.2014.02.001.

Royston, P., Sauerbrei, W., 2018. Multivariable modeling with cubic regression splines: A principled approach. The Stata Journal: Promoting communications on statistics and Stata 7 (1), 45-70. doi:10.1177/1536867X0700700103.

Scheaf, D.J., Davis, B.C., Webb, J.W., Coombs, J.E., Borns, J., Holloway, G., 2018. Signals' flexibility and interaction with visual cues: Insights from crowdfunding. Journal of Business 
Venturing 33 (6), 720-741. doi:10.1016/j.jbusvent.2018.04.007.

Short, J.C., Anglin, A.H., 2019. Is leadership language 'rewarded'in crowdfunding? Replicating social entrepreneurship research in a rewards-based context. Journal of Business Venturing Insights, 11, e00121. doi:10.1016/j.jbvi.2019.e00121.

Simonson, I., 1990. The effect of purchase quantity and timing on variety-seeking behavior. Journal of Marketing Research, 27 (2), 150-162.doi:10.1177/002224379002700203.

Skirnevskiy, V., Bendig, D., Brettel, M., 2017. The influence of internal social capital on serial creators' success in crowdfunding. Entrepreneurship Theory and Practice 41 (2), 209-236. doi:10.1111/etap.12272.

Soublière, J. F., \& Gehman, J., 2019. The legitimacy threshold revisited: How prior successes and failures spill over to other endeavors on kickstarter. Academy of Management Journal, (in press). https://doi.org/10.5465/amj.2017.1103

Stanko, M.A., Henard, D.H., 2017. Toward a better understanding of crowdfunding, openness and the consequences for innovation. Research Policy 46 (4), 784-798. doi:10.1016/j.respol.2017.02.003.

Suddaby, R., Bruton, G. D., \& Si, S. X., 2015. Entrepreneurship through a qualitative lens: Insights on the construction and/or discovery of entrepreneurial opportunity. Journal of Business Venturing, 30 (1), 1-10. doi:10.1016/j.jbusvent.2014.09.003.

Taeuscher, K., Bouncken, R. B., Pesch, R., 2020. Gaining legitimacy by being different: Optimal distinctiveness in crowdfounding. Academy of Management Journal, (in press). https://doi.org/10.5465/amj.2018.0620

Taylor, S.E., Pham, L.B., Rivkin, I.D., Armor, D.A., 1998. Harnessing the imagination: Mental simulation, self-regulation, and coping. American Psychologist 53 (4), 429-439. doi:10.1037/0003-066X.53.4.429. 
Thompson, D.V., Hamilton, R.W., Petrova, P.K., 2009. When mental simulation hinders behavior: The effects of process-oriented thinking on decision difficulty and performance. Journal of Consumer Research 36 (4), 562-574. doi:10.1086/599325.

Thompson, D.V., Hamilton, R.W., Rust, R.T., 2005. Feature fatigue: When product capabilities become too much of a good thing. Journal of Marketing Research 42 (4), 431-442. doi:10.1509/jmkr.2005.42.4.431.

Trope, Y., Liberman, N., 2003. Temporal construal. Psychological review 110 (3), 403-421. doi:10.1037/0033-295X.110.3.403.

Trope, Y., Liberman, N., 2010. Construal-level theory of psychological distance. Psychological review 117 (2), 440-463. doi:10.1037/a0018963.

Trope, Y., Liberman, N., Wakslak, C., 2007. Construal levels and psychological distance: Effects on representation, prediction, evaluation, and behavior. Journal of Consumer Psychology 17 (2), 83-95. doi:10.1016/S1057-7408(07)70013-X.

Tumasjan, A., Welpe, I., Spörrle, M., 2013. Easy now, desirable later: The moderating role of temporal distance in opportunity evaluation and exploitation. Entrepreneurship Theory and Practice, 37 (4), 859-888. doi: 10.1111/j.1540-6520.2012.00514.x.

Vallacher, R.R., Wegner, D.M., 1987. What do people think they're doing?: Action identification and human behavior. Psychological Review 94 (1), 3-15. doi:10.1037/0033-295X.94.1.3. van Balen, T., Tarakci, M., Sood, A., 2019. Do disruptive visions pay off?: The impact of disruptive entrepreneurial visions on venture funding. Journal of Management Studies 56 (2), 303-342. doi:10.1111/joms.12390.

van Werven, R., Bouwmeester, O., Cornelissen, J.P., 2015. The power of arguments: How entrepreneurs convince stakeholders of the legitimate distinctiveness of their ventures. Journal of Business Venturing 30 (4), 616-631. doi:10.1016/j.jbusvent.2014.08.001. 
van Werven, R., Bouwmeester, O., \& Cornelissen, J.P., 2019. Pitching a business idea to investors: How new venture founders use micro-level rhetoric to achieve narrative plausibility and resonance. International Small Business Journal, 37 (3), 193-214. doi:10.1177/0266242618818249.

Wentzel, D., Henkel, S., Tomczak, T., 2010. Can I live up to that ad? Impact of implicit theories of ability on service employees' responses to advertising. Journal of Service Research, 13 (2), 137-152. doi:10.1177/1094670510363304

Zhao, M., Hoeffler, S., Zauberman, G., 2007. Mental simulation and preference consistency over time: The role of process- versus outcome-focused thoughts. Journal of Marketing Research 44 (3), 379-388. doi:10.1509/jmkr.44.3.379. 
Appendix A - Overview of variables employed in Study 2

\begin{tabular}{|c|c|c|}
\hline Dependent Variables & Operationalization & $\underline{\text { Related Literature }}$ \\
\hline Funding success & $\begin{array}{l}\text { Dichotomous variable indicating whether the campaigns had reached their funding goal }(0=\text { funding } \\
\text { goal not reached, } 1=\text { funding goal reached }) \text {. Mean: .47; S.D.: .49 }\end{array}$ & - \\
\hline Funding amount raised & $\begin{array}{l}\text { The amount of funding the campaigns had raised (as the natural logarithm). Mean: 59,312; S.D.: } \\
152.244\end{array}$ & - \\
\hline Explanatory Variables & & - \\
\hline Product Stage & $\begin{array}{l}\text { We asked the coders to rate the campaigns in terms of their product development stage (idea stage }= \\
1 \text {; concept stage }=2 ; \text { prototype stage }=3 \text {; market-ready stage }=4) . \text { Mean: } .46 \text { (dichotomized); } 3.49(4 \\
\text { categories); S.D.: .49 }\end{array}$ & - \\
\hline Temporal distance & $\begin{array}{l}\text { Number of months between the campaign start and the projected delivery for the product that was } \\
\text { published on the campaign website (as the natural logarithm). Mean: } 4.08 \text {; S.D.: } 2.89\end{array}$ & - \\
\hline Ethnicity & $\begin{array}{l}\text { Dummy variable indicating whether the crowdfunder belonged to an ethnic minority or whether an } \\
\text { ethnic minority was on the team. Mean: .31; S.D.: .46 }\end{array}$ & Davis et al., 2017; Allison et al., 2017 \\
\hline Gender & $1=$ Female on the team; $0=$ otherwise. Mean: $.28 ;$ S.D.: .45 & Davis et al., 2017; Anglin et al., 2018a/b \\
\hline Business skills & $\begin{array}{l}\text { We asked our coders to rate the skills of the team on six items ("The creator(s) seem(s) to have: } \\
\text {...financial know-how...risk awareness...social competence... execution skills...creative } \\
\text { skills...technical skills", } \alpha=.88 \text { ). 7-point Likert scale: Mean: 4.28; S.D.: } 1.34\end{array}$ & Oo et al. 2018; Allison et al., 2017 \\
\hline Education & Team's highest education level. $1=$ Master's degree; $0=$ otherwise Mean: .23; S.D.: .42 & Anglin et al., 2018a; Allison et al., 2017 \\
\hline Team size & The number of team members indicated in the campaign. Mean: 2.11 ; S.D.: 1.24 & Allison et al., 2017 Oo et al., 2018 \\
\hline Project duration & Days between first day of campaign and last day of campaign. Mean: 32.6; S.D.: 7.33 & $\begin{array}{l}\text { Colombo, Franzoni, and Rossi-Lamastra } \\
\text { 2015; Oo et al., } 2018\end{array}$ \\
\hline $\begin{array}{l}\text { Backed Crowdfunding } \\
\text { Campaign }\end{array}$ & $\begin{array}{l}\text { Variable indicating the number of crowdfunding campaigns entrepreneurs had backed before starting } \\
\text { their own campaign (as the natural logarithm). Mean: 5.66; S.D.: } 15.08\end{array}$ & $\begin{array}{l}\text { Marelli and Ordanini 2016; Skirnevskiy et } \\
\text { al., } 2017 .\end{array}$ \\
\hline Novelty of the product & $\begin{array}{l}\text { Average of five items ("The product: ...provides radical differences from existing solutions, .... seems } \\
\text { really "out of the ordinary", ...can be considered as revolutionary, ...is stimulating, ...shows an } \\
\text { unconventional way of solving problems", } \alpha=.90 \text { ). 7-point Likert scale: Mean: } 3.15 ; \text { S.D.: }\end{array}$ & Im and Workman 2004 \\
\hline $\begin{array}{l}\text { Usefulness of the information } \\
\text { presented in the campaign }\end{array}$ & $\begin{array}{l}\text { Average of five items ("The information presented on this project page: ... highlights the product's } \\
\text { benefits, ...does a good job in building the product's image, ... is relevant, ... is well organized, ... is } \\
\text { professional", } \alpha=.93 \text { ). 7-point Likert scale: Mean: } 4.40 ; \text { S.D.:1.42 }\end{array}$ & $\begin{array}{l}\text { Allison et al, 2017; Chan and } \\
\quad \text { Parhankangas, } 2017\end{array}$ \\
\hline Aesthetic appeal of campaign & $\begin{array}{l}\text { Average of three items ("To what extent do you agree that the product presentation is: ....impressive, } \\
\text {...fascinating, ... creative", } \alpha=.93 \text { ). } 7 \text {-point Likert scale: Mean: } 3.08 \text {; S.D.: } 1.50\end{array}$ & $\begin{array}{l}\text { Allison et al., 2017; Parhankangas and } \\
\text { Renko, } 2017\end{array}$ \\
\hline Quality of the video & $\begin{array}{l}\text { Average of five items ("The video: ...is believable, ...has high image quality, ...is visually } \\
\text { interesting, ...is memorable }, \ldots \text { is original", } \alpha=.90) .7 \text {-point Likert scale: Mean: 4.10; S.D.: } 1.49\end{array}$ & $\begin{array}{l}\text { Anglin et al., 2018a/b; Chan and } \\
\text { Parhankangas, } 2017\end{array}$ \\
\hline
\end{tabular}

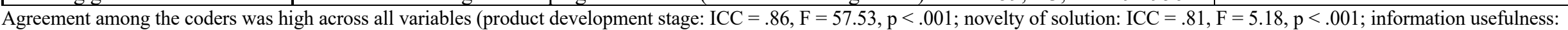

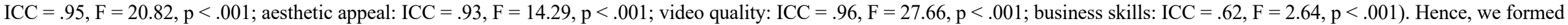
average scores for all variables. 
Appendix B - Summary of empirical results for pre-tests and hypotheses

\begin{tabular}{|c|c|c|}
\hline \multicolumn{3}{|c|}{$\underline{\text { Pre-Tests }}$} \\
\hline & $\begin{array}{l}\text { Reward-based crowdfunding campaigns that display } \\
\text { products in a less advanced development stage .... }\end{array}$ & Confirmation \\
\hline Assumption 1 & will elicit greater psychological distance & Yes \\
\hline \multirow[t]{2}{*}{ Assumption 2} & $\begin{array}{l}\text { will elicit greater desirability-related (vs. feasibility- } \\
\text { related) concerns }\end{array}$ & Yes \\
\hline & $\begin{array}{l}\text { Reward-based crowdfunding campaigns that claim to } \\
\text { deliver the products in the distant future... }\end{array}$ & \\
\hline Assumption 3 & will elicit greater psychological distance & Yes \\
\hline Assumption 4 & $\begin{array}{l}\text { will elicit greater desirability-related (vs. feasibility- } \\
\text { related) concerns }\end{array}$ & Yes \\
\hline \multicolumn{3}{|c|}{$\underline{\text { Direct Effects }}$} \\
\hline & $\begin{array}{l}\text { Reward-based crowdfunding campaigns that display } \\
\text { products in a less advanced development stage .... }\end{array}$ & Confirmation \\
\hline \multirow[t]{2}{*}{ Hypothesis 1a } & are less likely to receive support from potential backers. & Yes \\
\hline & $\begin{array}{l}\text { Reward-based crowdfunding campaigns that claim to } \\
\text { deliver the products in the distant future... }\end{array}$ & \\
\hline Hypothesis $1 \mathrm{~b}$ & are less likely to receive support from potential backers. & Yes \\
\hline \multicolumn{3}{|c|}{$\underline{\text { Mediation Effects }}$} \\
\hline Hypothesis 2 & $\begin{array}{l}\text { The effects of product development stage and time to } \\
\text { delivery on willingness to support are mediated by } \\
\text { psychological distance. }\end{array}$ & Yes \\
\hline \multicolumn{3}{|c|}{ Interaction Effects } \\
\hline & For campaigns that ... & Confirmation \\
\hline Hypothesis 3a (a) & $\begin{array}{l}\text { display products in a less advanced development stage, } \\
\text { outcome simulation will lead to a greater willingness to } \\
\text { contribute to the campaign than will process simulation. }\end{array}$ & Yes \\
\hline Hypothesis 3a (b) & $\begin{array}{l}\text { claim to deliver the product in the distant future, outcome } \\
\text { simulation will lead to a greater willingness to contribute } \\
\text { to the campaign than will process simulation. }\end{array}$ & Yes \\
\hline Hypothesis 3b (a) & $\begin{array}{l}\text { display products in a more advanced development stage, } \\
\text { process simulation will lead to a greater willingness to } \\
\text { contribute to the campaign than will outcome simulation }\end{array}$ & No \\
\hline Hypothesis 3b (b) & $\begin{array}{l}\text { claim to deliver the product in near future, process } \\
\text { simulation will lead to a greater willingness to contribute } \\
\text { to the campaign than will outcome simulation. }\end{array}$ & No \\
\hline
\end{tabular}

